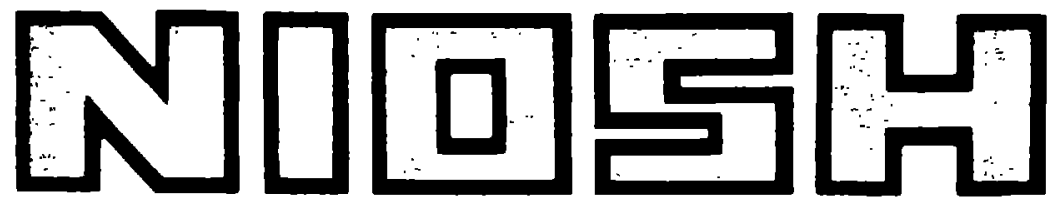

TECHNICAL INFORMATION

Statistical Methods for the

Determination of Noncompliance with Occupational Health Standards

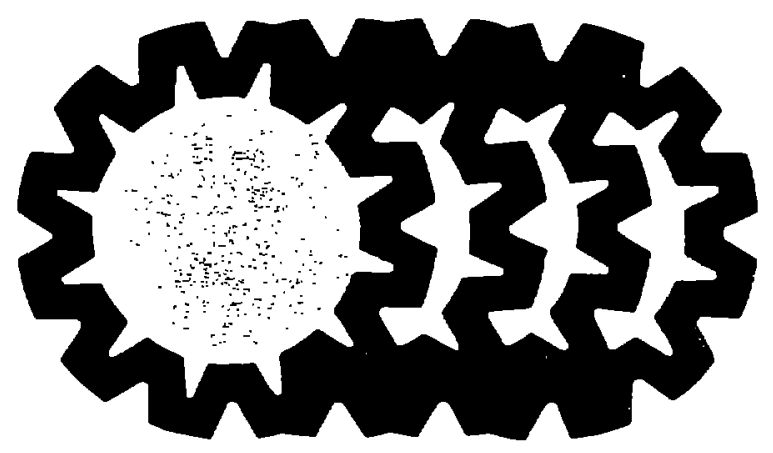




\title{
STATISTICAL METHODS FOR THE DETERMINATION \\ OF NONCOMPLIANCE WITH OCCUPATIONAL HEALTH STANDARDS
}

Nelson A. Leidel

and

Kenneth A. Busch

\author{
U.S. DEPARTMENT OF HEALTH, EDUCATION, AND WELFARE \\ Public Health Service \\ Center for Disease Control \\ National Institute for Occupational Safety and Health \\ Division of Laboratories and Criteria Development \\ Cincinnati, Ohio 45202
}

April 1975

Fo wale by the Superintendent of Documents, U.S. Government

Print Ing Oflice, Wablingt on, D.C. 20402 
Mention of company or product names is not to be considered as an endorsement by NIOSH.

(Formerly NIOSH TR-76)

HEW Publication No.(N1OSH) 75-159 


\section{PREFACE}

The first NIOSH recommendations concerning statistical methods for the determination of compliance with an occupational health standard appeared in 1972 in the NIOSH Criteria Document "Occupational Exposure to Carbon Monoxide," HSM 73-11000 (pp. VIII-2 and 3). Subsequent research and an analysis of existing literature demonstrated that the assumptions made for the above method were inappropriate. Since 1972, research work has continued in NIOSH, both in-house and contracts, with the goal of developing practical statistical methodology which can be applied to the problems of sampling strategy and decision making in regard to occupational health employee exposure standards.

This report presents the first results of NIOSH work on predictive and analytical statistical methods in the field of industrial hygiene. Other reports will follow with more extensive presentations of techniques and statistical theory. This technical report is concerned solely with noncompliance statistics and is oriented toward the governmental compliance officer. However, the conclusions regarding sampling strategy are equaliy applicable to employers and industry industrial hygienists. 


\section{ACKNOWLEDGEMENTS}

The authors wish to gratefully acknowledge the many reviews, suggestions, and constructive criticisms that contributed to this report. Special thanks are due Jeremiah Lynch, Bill Kelley, and Paul Roper for their extensive reviews of the many versions of this work. Additional thanks are due Chuck Atkins, Jeff Burton, Kathy Carlberg, Lorice Ede, Dave Huebner, Dick Kupe1, Lee Larsen, Gus Lauman, Chuck McCammon, Ann Saalwaechter, and Jay Chmiel for their contributions. John Bryant and Dr. Herb Stokinger provided much encouragement and motivation to the authors toward the completion of this report.

Finally, very special thanks are due Myra Brooks, Mary Geimeier, and Pat Zehnder for their patient typing of the drafts of this report. 
TABLE OF CONTENTS

Abstract ............................ vi

Nonmenclature ................... viii

Introduction ................... 1

Normal and Log-normal Frequency Distributions. . . . . . . 3

Compliance vs. Noncompliance Statistic's . . . . . . . . . 5

Sampling Strategy .................. 5

Sample Duration ................ . 6

Number of Samples ................. . . 8

Sampling Periods................. . 10

Ceiling Standards.................... 12

Treatment of Gas Detector Tube Data ............ 13

Procedures for Data Analysis . . . . . . . . . . . 14

Full-Period Single-Sample Procedure . . . . . . . 16

Ful1-Period Consecutive Samples Procedure ........ 18

Partial-Period Consecutive Sample(s) Procedure . . . . . 19

Grab Samples Data Analysis............. 20

Examples of Procedures

Example \#1 for Full-Period Consecutive Samples Procedure . . . 21

Example \#2 for Full-Period (Ceiling) and Partial Period

Consecutive Samples Procedures............. 22

Example \#3 for Full-Period Consecutive Samples Procedure . . . 25

References .................... 27

figures ..................... 31 
TABLE OF CONTENTS (CONT.)

Appendix A - Grab Samples Procedure ............... 39

0.0 - Nomenclature ................ 40

1.0 - Introduction .................. 41

2.0 - Description of procedure ............ 42

3.0 - Examples of procedure ............ 43

4.0 - Decision chart and estìmation nomographs ....... 52 


\section{ABSTRACT}

Procedures are presented for determining if the $95 \%$ Lower Confidence Limit of the concentration of a contaminant in an occupational environmental air sample or of the arithmetic average for a group of such samples exceeds an occupational health standard. The determination can be made with a known maximum probability of making an incorrect decision that a state of noncompliance exists. Recommendations are given concerning the duration of samples, the number of samples to take and the period(s) during the work day when the samples should be collected. The advantages of a full-period sample (or consecutive samples) over the mean of several grab samples are discussed.

When the true arithmetic average air concentration is estimated from the mean of a group of random grab samples the log-normal distribution is assumed for the individual grab samples. When only one sample is examined or when one or several samples are taken for the entire time period for which a standard is defined the normal distribution is assumed. In the latter cases, variability over time is absent, but sampling and analytical errors are present. 
NOMENCLATURE

C.V. coefficient of variation, a measure of relative dispersion, also known as the relative standard deviation $=s / x$

GM geometric mean $=(10)^{\bar{x}} \ell$

GSD geometric standard deviation $=(10)^{\mathrm{s} \ell}$

LCL lower confidence limit ( $95 \%$ one-sided) of a data value or of the arithmetric mean of a group of normally or lognormallv distributed samples

$n \quad$ number of measurements being analyzed

s standard deviation of original data

$S_{\ell} \quad$ standard deviation of logs 10 of original data

std occupational health employee exposure standard such as the federal standards in 29 CFR 1910.93

TWA time weighted average emplovee exposure as defined in 29 CFR 1910.93(d)(1)

$x_{i} \quad$ a single air concentration measurement from a aroup of such measurements

$\mathrm{T}_{i} \quad$ time duration of a single sample

$T \quad$ total time duration for a group of $n$ samoles

$\bar{x} \quad$ arithmetic mean of a group of air concentration measurements $x_{i}$

$\bar{x}_{l} \quad$ arithmetic mean of the $\operatorname{logs}_{10}$ of the original data 
$\sigma \quad$ standard deviation of a sampling/analytical method which is well. known from prior data

$\sigma_{\bar{x}} \quad$ standard deviation of $\bar{x}$

¿x sum of a group of air concentration measurements over all $n$ values 


\section{INTRODUCTION}

The objective of this paper is to present sound statistical procedures for the collection and evaluation of sample results to determine if a state of noncompliance with an occupational health standard exists. We will present procedures for calculating the $95 \%$ Lower Confidence Limit (LCL) of an occupational environmental sample or the arithmetic average of a group of such samples. One may then compare the results of occupational environmental sampling to an occupational health standard and make a decision with a known chance of making an incorrect decision that a state of noncompliance exists.

The occupational health standard may be either an 8-hour time-weighted average (TWA) or ceiling standard defined for a short time interval (generally 30 minutes or less). It should be emphasized that numerical calculations are necessary only if the sample mean is greater than the standard.

This technical report was written primarily to serve as a handbook for governmental industrial hygienists and compliance officers, both state and federal, who are responsible for making decisions in regard to noncompliance with occupational health standards. To accomplish this goal the report contains many examples of the recommended procedures. Also several nomograms are presented to speed calculation of results if a desk calculator is not available.

The report treats only the statistical analysis of occupational environmental data. Topics such as choice of sampling location, mobility of the worker, variation in work procedures and processes, appropriate application of the standard to the process being sampled, and finally appropriate selection of breathing zone, personal and/or area samples are not treated in this report. In all cases one must avoid the trap of falling into a "numbers game" and keep in proper perspective what the data represents in relation to what the worker is exposed to.

Roach $(1,2,3)$ recognized the fact that a small number of occupational environmental samples can only yield an estimate of the true mean air concentration of the substance sampled. He pointed out that, due to the uncertainly in the mean value obtained from only a few samples, allowance must be made for this uncertainty when comparing the mean with the occupational health standard in determining whether a condition of non-compliance exists.

However, Roach and others have made the mistake of assuming that all occupational environmental data was best described by the normal distribution. Recent work has shown that occupational environmental data is usual$1 y$ better described by fitting a log-normal distribution to the measurements. But random sampling and analytical errors tend to be more nearly normally 
distributed so that this distribution can be used when only one sample is examined or when a sample or several samples are taken for the entire time period for which the standard is defined.

In all cases the arithmetic mean of the data is the best descriptor of the average concentration to which a man is exposed. The variability of the data is accounted for by calculating the 95\% Lower Confidence Limit (LCL) on the sample or arithmetic mean of a group of samples. The log-normal distribution is assumed if the samples are "grab" samples (several samples taken for a small fraction of the time period for which the standard is defined).

The statistical procedures presented below will not detect and do not allow for analysis of highly inaccurate results, i.e., systematic (nonrandom) errors or mistakes. The detection and elimination of mistakes is primarily a technical rather than a statistical problem. To assure accurate results one must have an instrument calibration program and a quality control program for laboratory analysis. Systematic errors must also be known ahead of time whether from the instrument calibration procedure or the laboratory quality control program. If a constant systematic error is known to exist in an instrument or analytical procedure then correct the sample mean of the data before analyzing for noncompliance. 
NORMAL AND LOG-NORMAL FREQUENCY DISTRIBUTIONS

Before sample data can be statistically analyzed we must have knowledge of the frequency distribution of the results or some assumptions must be made. Roach $(1,2,3)$ and Kerr (4) have assumed that environmental data is normally distributed. However, it is well established $(5,6,7,8)$ that most comunity air pollution environmental data is better described by a log-nomal distribution. That is, the logarithms (either base e or base 10) of the data are approximately normally distributed. Most importantly, Breslin, et al (9), Sherwood $(10,11)$, Jones and Brief $(12)$, Gale $(13,14)$, Coenen $(15,16)$, Hounam $(17)$, and Juda and Budzinski $(18,19)$ have shown that occupational environmental data from both open air and confined work spaces for both short (seconds) and long (days) time periods are log-normally distributed.

What are the differences between normal and log-normally distributed data? First, it should be remembered that a "normal" distribution is completely determined by two parameters: 1) the arithmetic mean ( $\mu$ ) and 2) the standard deviation $(\sigma)$ of the distribution. On the other hand, a "log-normal" distribution is completely determined by 1) the median or geometric mean (GM) and 2) the geometric standard deviation (GSD). For log-nomally distributed data, a logarithmic transformation of the original data is normally distributed. The GM and GSD of the log-normal distribution are merely antilogs of the mean and standard deviation of the logarithmic transformation. Normally distributed data has a symmetrical distribution curve while log-normally distributed environmental data is generally positively skewed (1ong "tail" to the right indicating a larger probability of very large concentrations than for normally distributed data). Figure 1 compares a log-normal distribution to a normal distribution that has the same arithmetic mean $(\mu)$ and standard deviation $(\sigma)$.

The conditions conducive to (but not all necessary for) the occurrence of log-normal distributions are found in occupational environmental data. These conditions are (15):

1) the concentrations cover a wide range of values, often several orders of magnitude,

2) the concentrations 1 ie close to a physical limit (zero concentration),

3) the variability of the measured concentration is of the order of the size of the measured concentration and,

4) there is a finite probability of very large values (or data "spikes") occurring

The variability of occupational environmental data (differences between repeated measurements at the same site) can usually be broken into three major components: 1) random errors of the sampling method, 2) random errors of the analytical method and 3) variability of the environment with time. The first two components of the variability are usually known in advance and are approximately nomafly distributed. However, the environ- 
mental fluctuations of a contaminant in a plant usually greatly exceed the variability of known instruments (often by factors of 10 or 20 ). The above components of variability were discussed in an article by LeClare, et. al. (20).

When several samples are taken in a plant to determine the average concentration of the contaminant and estimate the average exposure of an employee then the log-normal distribution should be assumed. However, the normat distribution may be used th the speciat cases of 1) taking a sample to check compliance with a ceiling standard and 2) when a sample (or samples) is taken for the entire time period for which the standard is defined (be it 15 minutes or eight hours). In these cases the entire time interval of interest is represented in the sample and only sampling and analytical errors are present.

Both Coenen $(15,16)$ and Sherwood (11) state that the the arithmetic mean of the data must be used in the assessment of measurement results because the arithmetic mean is the best descriptor of the average concentration to which a man is exposed. However, when the arithmetric mean $(\bar{x})$ for a group of samples is compared to a standard to determine if a state of noncompliance exists the variability of the data must be taken into account. This can be done by calculating the 95\% Lower Confidence Limit (LCL) on the arithmetic mean of the group of samples whether the samples are normally or log-normally distributed. In order to statistically demonstrate a condition of noncompliance the LCL must exceed the standard as shown in Figure 2. If the LCL is below the standard then noncompliance cannot be shown, but compliance is not necessarily proven. More will be said about this later. of course, if $(\bar{x})$ itself is below the standard, it is unnecessary to calculate the LCL or perform any formal statistical test.

Both Coenen (15) and Juda and Budzinski $(18,19)$ have given equations for confidence limits on the arithmetic mean of a log-normal distribution. However in both cases simplifying assumptions had to be made. Coenen 's (15) assumption concerning the distribution of individual errors seemed to have questionable statistical basis. Juda and Budzinski $(18,19)$ equated the arithmetic mean and the geometric mean in order to arrive at approximate confidence 1 imits.

Since both of the above approaches utilized questionable approximations it was decided to use only rigorous statistical theory. A NIOSH contractor, Systems Control, Inc. has developed a procedure that uses a decision chart rather than calculating the $\operatorname{LCL}(21,22)$. The procedure uses original data normalized to the standard and the variability of the actual data. This procedure is presented as Appendix $A$ of this report. 
The one-sided statistical tests given in this report are only for the purpose of determining if a condition of noncompliance exists. If the test yields a non-significant result, one cannot conclude that a condition of compliance exists, but rather, only that insufficient evidence for noncompliance is available. Thus, there are two alternatives in the case of a nonsignificant result. First, a condition of compliance might exist. But there is also the possibility that enough measurements are not available to definitively answer the question one way or the other. Additional statistical theory not presented here must be used to evaluate the latter two possibilities.

Simply stated, statistics for noncompliance are oriented toward the governmental compliance officer and are used to make a decision on data that occurred on a particular day. The statistical tests are designed to 1 imit the maximum "risk" (probability) to 5\% of making a wrong decision. i.e. the risk of deciding for noncompliance when in fact the process sampled is in compliance. Leidel (23) has discussed the selection of an approprlate level of risk for these type statistical tests and the interaction between the protection levels afforded the employer and employee.

This technical report is concerned solely with such noncompliance statistics. Conversely, statistics for compliance are oriented toward the employer or industrial hygiene consultant to a company. The National Institute for Occupational Safety and Health currently has underway a contract with Systems Control, Inc. of $\mathrm{Pa} 10 \mathrm{Alto}, \mathrm{Ca}$. regarding "Sequential Sampling Plans and Decision Theory for Employer Monitoring of Employee Exposures to Industrial Atmospheres" (CDC-99-74-75). The contractor is developing a manual that adapts appropriate sampling/decision theory into a simplified procedure which can be used by non-statistically trained employers or their representatives. This manual should be available in the summer of 1975.

However, there already exists in the literature several articles on compliance statistics. Jones and Brief (12) give an excellent discussion of how to plot log-normal occupational environmental data and interpret the resulting graph. Sherwood (11) and Coenen (15) also discuss how to interpret sample data from a log-normal distribution.

\section{SAMPLING STRATEGY}

In trying to assess an occupational environment and estimate employee exposures three important questions must first be answered concerning the sampling strategy. Over how long a period should each sample be taken (sample duration)? How many samples should we take? Finally, at what times during the day should we take the samples? 
Sample Duration

For some grab sample devices the sampling period is predetermined. Colorimetric detector tubes are an example. There is a direct reading dust monitor that samples for a fixed one minute period. Some substances such as asbestos $(24,25)$ may require certain sampling times to attain the best results during the analytical procedure. In many cases though we have a choice of a wide range of sampling times from a few seconds to eight hours. Intuitively we might feel that lengthening the sample period would significantly increase the certainty of the information we collect. That is we would say that an increase in sample time would lower the variability of the data and reduce the width of the confidence limits on the mean, thereby yielding a "better" answer. However, the above assumption is almost completely false for short term grab samples.

Coenen (16) derived a relation that showed the reduction in dispersion (corresponding to the variance of Gaussian random processes) as a function of increase in sampling time. He concluded that data variability (dispersion) decreases only slightly with sampling time and that an increase in sampling time even by a factor of ten is usually not worthwhile. Using Coenen's relation Table 1 was developed, assuming typical autocorrelation coefficients of 0.9 and 0.7 between consecutive samples of length equal to the basic period.

Table 1 - Possible \% reduction in standard deviation of individual short-term grab samples with increasing sampling durations

multiple of basic
sampling period

$$
2
$$

10 possible \% reduction in standard deviation

The overall sample variance is the sum of a) the sampling method variance, b) the analytical method variance, and c) the environmental concentration variance. The data of Larsen, et. al. (26) showed percentage reductions in geometric standard deviations (GSD) similar to those in Table 1. LeClare, et. a1. (20) found similar reductions and concluded that the small reductions obtained in the longer term sample variances were due to the 1 imiting effect of the analytical method variance. Therefore the primary consideration in selecting short sampling times should be the analytical method. Each analytical method requires a minimum amount of material. This should be known in advance and the sample period selected accordingly. Any increase in the sampling period past the minimum time required to collect an adequate amount of material is unnecessary and unproductive. 
Saltzman (27) concluded that the choice of sampling time is " . . . an important decision affecting the results." This is true if we are trying to gather detailed information of the true component fluctuations in air concentrations. However when attempting to make a decision on a possible noncompliance situation it is better to take shorter samples because this allows us to take more samples in a given day. We shall see that it is much more important to collect several samples of short duration than to collect one medium length sample covering the same total sampling period. This is true because the random analytical/sampling errors can be "averaged out" (along with the longer-term environmental fluctuations during the sampling day) by taking a mean of random independent short samples.

The limiting case of the above occurs if we have the ability to sample for nearly $100 \%$ of the time period for which the standard is defined. If we can sample for the entire length of the standard's averaging period or close to it (with either one or several consecutive samples) we can obtain a better estimate of the true average employee exposure. This is because we only have to contend with the sampling/analytical errors which are much smaller than the environmental fluctuations which affect short term samples. Thus, there is a marked advantage in using a single full-period sample (or consecutive samples over the full period) when attempting to demonstrate noncompliance. It is much more difficult to demonstrate noncompliance using the mean of several grab samples because the additional variability due to the environmental fluctuations lowers the LCL. This is shown in Figure 3 which demonstrates the effect of the number of grab samples on requirements for demonstration of noncompliance.

The family of three curves are for various levels of data variability as measured by geometric standard deviations (GSD) ranging from 1.5 to 3.0 $\left(s f^{=0.176}\right.$ to 0.477$)$. Fortunately much industrial hygiene data have GSDs of 1.5 to 2.5. For this range of GSDs and sample sizes of 3 to 10 , one must generally obtain a measured average exposure of 1.2 to 2.5 times the standard in order to demonstrate noncompliance. For GSDs greater than 3.0 it is very difficult to show noncompliance because the observed mean exposure has to be so far above the standard. Figure 3 is based on the procedure presented in Appendix A.

However, if we use a full-period sample (or consecutive samples) in attempting to demonstrate noncompliance, the amount the observed mean must be above the standard is much lower. Figure 4 shows the effect of consecutive full-period sample size on requirements for demonstration of noncompliance. The five curves are for various sampling/analytical coefficients of variation (CV) ranging from 0.05 to 0.25 . See Table 2 for typical CVs. For the range of typical CVs and sample sizes of 1 to 4 , one must have an average concentration of 1.05 to 1.41 times the standard in order to demonstrate noncompliance. Suppose we are able to take four consecutive 2-hour samples for asbestos. The Full-Period Consecutive Samples procedure (and Figure 4) shows that for asbestos ( $\mathrm{CV}=0.22$, Table2) the mean of the four samples has to be only $18 \%$ above the standard to show noncompliance. Single asbestos samples taken for comparison with the ceiling standard have to be $36 \%$ above the standard to show noncompliance. 
Number of Samples

The question of how many samples to take is vital since it relates directly to the confidence we have in our resulting estimate of the mean air concentration and employee exposure. We see the effect of sample size on requirements for demonstration of noncompliance in Figures 3 and 4 . For grab samples (Figures 3 ) the curves for GSDs of 1.5 to 2.5 change relatively slowly after sample sizes of 7 to 8 . For full-period consecutive samples (Figure 4 ) a similar leveling off occurs of the curves relating the value of $\bar{x} / \mathrm{std}$. required to demonstrate noncompliance to sample size.

For full-period consecutive samples, Figure 4 shows that based on statistical considerations alone, a suitable number of samples is around four to seven. However, practicality and costs of sampling and analys is must be considered. Most long duration sampling methods cannot be run for longer than about 4 hours per sample. Thus most full-period consecutive sampling strategles would obtain at least two samples when an 8-hour average standard is sampled for. If one had a sampling/analytical technique with a C.V. of $10 \%$, Figure 4 shows that the $x / s$ td required to demonstrate noncompliance decreases from about 1.12 for 2 samples to about 1.06 for 7 samples. Or for 2 samples we can demonstrate noncompliance when the mean of the 2 samples is $12 \%$ above the standard. But with 7 samples we can demonstrate noncompliance when the mean of 7 samples is $6 \%$ above the standard. Above seven samples the small decrease obtained in variability is not normally justified when compared to the time and effort required to obtain additional samples. There are theoretical benefits to be gained from larger sample sizes, but in terms of the disproportionately large additional costs incurred (especially analytical) the benefits are usually negligible. Thus on a cost benefit basis we can conclude that 2 consecutive full-period samples (about 4-hours each for an 8-hour average standard is the "best" number to take.

For grab samples, less than 4 samples lead to unreasonably large $\bar{x} /$ std ratios required to demonstrate noncompliance. As with consecutive full-period samples, Figure 3 shows there is a point of diminishing returns in attempting to reduce error in the mean by taking more than seven or so grab samples. However, since the level of variability in the mean of grab samples is usually much higher than for the same number of full-period samples, one might have to take many more than seven grab samples to attain the same level of precision afforded by even fewer than 4 to 7 full-period samples. Thus, we have a statistical criterion which can lead to economies in sampling by permitting reduction in sampling effort with a calculable degree of confidence. We can conclude that the optimum number of grab samples to be taken over the time period appropriate to the standard is 4 to 7 samples. 
Finally, Figure 5 demonstrates the Partial Period Consecutive Samples Procedure. The effect of sample size and total time covered by all samples on requirements for demonstration of noncompliance is shown by the family of four curves. A typical sampling/analytical CV of 0.10 is used for all curves. The bottom curve (8-hour total sample time) is the same curve as the $\mathrm{CV}=0.10$ curve of Figure 4 . The taking of partial period consecutive samples is a compromise between the preferred full-period sample(s) and the least desirable grab samples. If one assumes a GSD of 2.5 on Figure 3 , we see that a curve of about $51 / 2$ hours on Figure 5 would have approximately the same $\bar{x} /$ std ratios. Therefore if one cannot sample for at least $70 \%$ of the time period appropriate to the standard (5 1/2 hours for an 8-hour standard) it is better to go to a grab sampling strategy. 
Sampling periods

The last question to be answered concerns when to take the grab samples during the period of exposure. The accuracy of the probability level for the test depends upon implied assumptions of the log-normality and independence of the sample results which are averaged. These assumptions are not highly restrictive if precautions are taken to avoid bias when selecting the sampling times over the period for which the standard is defined. To this end, it is desirable to choose the sampling periods in a statistically random fashion. For a standard which is defined as a time-weighted average concentration over a period longer than the sampling interval, an unbiased estimate of the true average can be assured by taking samples at random intervals. It is valid to sample at equal intervals if the series is known to be stationary, i.e., if contaminant levels vary randomly about a constant mean and fluctuations are of short duration relative to length of the sampling interval. However, if means and their confidence limits were to be calculated from samples taken at equally spaced intervals, biased results could occur if cycles in the operation were in phase with the sampling periods. Results from random sampling are valid even when cycles and trends occur during the period of the standard. The word random refers to the manner of selecting the sample. Any particular sample could be the outcome of a random sampling procedure. A practical way of defining random sampling is that any portion of the work shift has the same chance of being sampled as any other.

What do we do if we can't sample during the entire work day or entire length of the operation? Strictly speaking, the measurement results are valid only for the duration of the period when the measurements were taken. However, professional judgement may allow inferences to be made about concentrations during other portions of the day. Reliable knowledge concerning the operation is required to make these types of extrapolations.

To select a true random sample, proceed as follows:

1) Divide the total period over which the standard is defined into (n) mutually exclusive (non-overlapping) intervals whose collective lengths equal the period for the standard. The number $(n)$ is equal to $(P / s)$, where $P$ is the period of the standard and $S$ is the length of sampling intervals.

For example, if 15-minute samples are taken and the standard is a timeweighted average over an 8-hour work period, there would be $n=32$ possible sampling intervals from which a random sample could be selected.

2) Number the possible sampling intervals consecutively: $1,2,3, \ldots$, , n. For example, for an 8-hour standard over a workday from 8:00 am to 4:30 pm with 12:00 N to 12:30 pm spent outside the work area for lunch, we would assign the following code numbers for 15-minutes sampling intervals. 


\begin{tabular}{cc} 
Code \# & Interval \\
\hline 1 & $8: 00-8: 15 \mathrm{am}$ \\
2 & $8: 15-8: 30 \mathrm{am}$ \\
3 & $8: 30-8: 45 \mathrm{am}$ \\
. & \\
. & \\
15 & $11: 30-11: 45 \mathrm{am}$ \\
16 & $11: 45-12: 00 \mathrm{~N}$ \\
17 & $12: 30-12: 45 \mathrm{pm}$ \\
18 & $12: 45-1: 00 \mathrm{pm}$ \\
. & \\
31 & \\
32 & $4: 00-4: 15 \mathrm{pm}$ \\
& $4: 15-4: 30 \mathrm{pm}$
\end{tabular}

3) If (n) random samples are to be taken, use a table of random numbers such as Table A-36 in Natrella (28). Select a "subjectively random" starting point and from there list the first $(n)$ different integers between 1 and $(n)$.

For example, suppose we want to select five random 15-minute sampling periods from 32 possible periods. Arbitrartily choose the first column and the eleventh row (67) from the first page of Natrella's (28) Table A-36 as our starting point. This page is reproduced in this report as Figure 6. Moving vertically downward in the table our five periods would be $24,6,29$, 16 , and 4 .

\begin{tabular}{c} 
Period \\
\hline 4 \\
6 \\
16 \\
24 \\
29
\end{tabular}

Time Interval

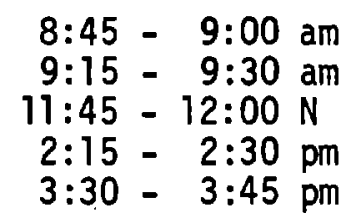

Juda and Budzinski (19) give a similar procedure. 


\section{CEILING STANDARDS}

Samples taken for determination of noncompliance with ceiling standards are treated in a manner similar to those taken for comparison with timeweighted average (TWA) standards. Two important differences should be noted.

The first point is that samples taken for comparison with ceiling standards are best taken in a nonrandom fashion. That is, all available knowledge relating to the area, individual, and process being sampled should be utilized to obtain samples during periods of maximum expected concentrations of the substance.

The second point is that samples taken for comparison to ceiling standards are normally taken for a much shorter time period than those taken for calculating time-weighted averages (TWA). There are three different ways in which the time period for a ceiling standard may be defined (29 CFR 1910.93) (see 29).

29 CFR 1910.93 (a)(1) for Table G-1:

No time period. "An employee's exposure. . .shall at no time exceed the ceiling value. . ."

29 CFR 1910.93 (b)(2) for Table G-2:

No time period, but peak above the "ceiling" allowed. "An employee"s exposure. . shall not exceed at any time during an 8-hour shift the acceptable ceiling concentration limit . . except for . . a maximum peak value.

29 CFR 1910.93 (b)(2) for Table G-2:

Short time period ( 5 to 30 minutes) defined as "maximum duration" for "maximum peak". The ceiling standard directly above may be exceeded for short periods up to a concentration defined as "acceptable maximum peak above the acceptable ceiling concentration for an 8-hour shift".

However under the current Joint NIOSH/OSHA Standards Completion Program all ceiling standard substances in Table G-1 of 29 CFR 1910.93 will have the standard defined for 15 minute time periods as:

"concentrations not in excess of . . averaged over any 15-minute period during an 8-hour work shift."

Measurements taken for the purpose of determining employee exposure to ceiling standard substances should be taken during periods of maximum expected airborne concentrations of the substance. Each measurement should consist of a 15-minute sample (or series of consecutive samples totaling 15 minutes) taken in the employee's breathing zone (air that would most nearly represent that inhaled by the employee). A minimum of 3 measurements should be taken on one work shift and the highest of all measurements taken is a good estimate of the employee's upper exposure for that shift. 
Taking 3 measurements on a shift makes it easier to spot gross errors or mistakes. However, in most cases only the highest value would be statistically tested for noncompliance by the Full-Period Sample Procedure. If the samples are taken for comparison to the "maximum peak" ceiling standard the sampling period should equal the "maximum duration" period for that particular standard. Thus, in the case of detector tubes it might be necessary to take several consecutive samples and average the results. Then the Full-Period Consecutive Samples Procedure would be used to analyze the results.

TREATMENT OF GAS DETECTOR TUBE DATA

Because gas detector tubes receive quite widespread usage in the industrial hygiene field and because their accuracy and precision have been subject of much controversy, it was decided to treat them separately. Under existing Federal Regulations (42 CFR Part 84) (see 30), stringent requirements are set forth for the construction and performance of gas detector tube units. One of the most important requirements pertains to the accuracy of the units. 42 CFR 84.20 (e) states:
"Accuracy of gas detector tubes shall be such that measurements made by these tubes, used in accordance with the applicant's instructions, are reliable to within plus or minus $25 \%$ of the actual value at concentrations of 1,2 , and 5 times the test standard of the contaminant of interest, and within plus or minus $35 \%$ of the actual value at one-half the test standard."

However, it is important to note that the above are maximum allowable error specifications and that the majority of tubes meeting all the construction and performance requirements of the proposed regulations will do considerable better than plus or minus $25 \%$ accuracy.

Johnson and Roper $(31,32,33,34)$ at the National Institute for Occupational Safety and Health have conducted performance studies to determine the reliability of hydrogen sulfide, chlorine, ozone, and trichloroethylene gas detector tubes. Data was taken from the above referenced four reports for the specific brands of gas detector tubes that met existing federal regulations and was subjected to an analysis of variance statistical procedure. The data involved in the analysis was for 31 "batches" (minimum of ten tubes per batch) from five manufacturers for four different gases at three concentration levels.

The analysis of the detector tube data showed that, after assuming variability is constant where concentrations are expressed as percentages of the true value, the total variability can be resolved into two components of variance:

1) Systematic batch errors (interbatch variation) with variance $\left(s^{2}\right)_{\text {sys }}$

2) Random (tube-to-tube) errors and other analytical errors (intrabatch variation) with variance $\left(s^{2}\right)$ tube 
The interbatch variation was found to have a mean for all batches relatively close to zero ( $95 \%$ confidence 1 imits: $0.7 \%$ to $6.9 \%$ ) as compared to the range of systematic errors from batch to batch. The interbatch variation had a standard deviation $s_{\text {sys }}=7.2 \%$. The intrabatch variation (tube-to-tube) had a standard deviation $5_{\text {tube }}=14.0 \%$.

However, the variance of actual environmental data will include both the variation due to environmental fluctuations and the random intrabatch (tubeto-tube) variations. Thus, the only variation that should be "added" to the data variation is the interbatch standard deviation of $7.2 \%$. But after the appropriate equations were derived and utilized, it was found that the standard deviation of actual data usually is much larger (by factors of 10 or 20 ) than the $7.2 \%$. It was found by ignoring the $7.2 \%$ in the calculations, the maximum error introduced was less than $5 \%$. Thus, we feel that the data for detector tubes can be adequately and confidently analyzed by the Grab Samples Procedure in Appendix A with no additional modifications. When the Full-Period Sample or Full-Period Consecutive Samples Procedure is used a coefficient of variation of $14 \%$ (from Table 2) should be used.

Procedures for Data Analysis

A single sample or the time-weighted average of several consecutive samples taken for the entire time period for which a standard is defined yields the "best" estimate of the true average concentration of the airborne contaminant. This type of sample is referred to as a "full-period" sample. Typically, a full-period sample would have to be 8 to $36 \%$ above the standard in order to demonstrate noncompliance with $95 \%$ confidence. The Full-Period Single Sample Procedure is used to calculate the $95 \%$ lower confidence 1 imit (LCL) for this type of sample. If several consecutive samples are taken for the entire time period of a standard the Full-Period Consecutive Samples Procedure is used to calculate the 95\% Lower Confidence Limit ( $(\mathrm{CL})$ for the arithmetic mean of the samples. The greater the number of consecutive samples, the less the mean of those samples has to be above the standard in order to demonstrate noncompliance. Thus, it is better to take two consecutive 4-hour samples than one 8-hour and better yet to take four consecutive 2-hour samples during an 8-hour period for which a standard is defined. This is true only if the costs of sample analysis are negligible or not considered.

In some cases it isn't possible to take the sample(s) for the entire period of the standard. If one samples for six to almost eight hours for an 8-hour standard, the sample(s) is referred to as a "partial period" sample(s). The sample (s) is analyzed in the same manner as a full-period sample(s), but the LCL is compared to a "partial period limit" as calculated by the Partial Period Consecutive Sample(s) Procedure. 
Finally, if long term (greater than one hour) samples are not practical one must estimate the average air concentration by several short term or grab samples. A suitable number of grab samples is at least four to seven. The Grab Samples Procedure is used to calculate the LCL for arithmetic mean of these samples. Samples taken for comparison to a TWA (time-weighted average) standard should be taken at random intervals over the period of the standard. However, samples taken for comparison with a ceiling standard should be taken during periods of maximum expected concentrations.

Equations for the various procedures are given in sections immediately following. Refer to Figure 7 when deciding what data analys is procedure should be used. 


\section{Ful1-Period Single Sample Procedure}

The following procedure should be used to determine noncompliance with either a TWA, ceiling, or excursion standard. It is used when only one sample is being tested. For a TWA standard the sample must have been taken for the entire period for which the standard is defined (usually 8 hours). The variability (standard deviation or coefficient of variation C.V.) of the sampling and analytical methods used to collect and analyze the sample must be well known from previous measurements. The statistical test given is one-sided comparison-of means test using the normal distribution at the $95 \%$ confidence level.

ONLY IF THE LCL OF THE SAMPLE EXCEEDS THE STANDARD ARE WE 95\% CONFIDENT THAT THE TRUE AVERAGE CONCENTRATION EXCEEDS THE STANDARD AND THAT A CONDITION OF NONCOMPLIANCE EXISTS.

$$
L C L=x-1.6450
$$

where $1.645=$ critical standard normal deviate for $95 \%$ confidence,

$$
\begin{aligned}
\sigma= & \text { standard deviation of sampling/analytical method } \\
& \text { which is well known from prior data, and } \\
x= & \text { measurement being tested. }
\end{aligned}
$$

If the coefficient of variation (C.V.) is known the LCL is computed from:

$$
L C L=x-((1.645)(C . V .)(\text { standard }))
$$

Figure 8 can be used to aid this calculation $(n=1)$. Some coefficients of variation are available from Table 2.

If the sample is taken for less than the entire period for which the standard is defined, refer to the Partial Period Sample Procedure which is a variation of the Full-Period Consecutive Samples Procedure. 
Table 2. Coefficients of Variation for Some Sampling/Analytical Procedures.

Sampling/Analytical

Colorimetric detector tubes

Rotameter on personal pumps

Charcoal tubes (sampling/analytical)

Asbestos (sampling/counting)

Respirable dust except coal mine dust (sampling/weighing)

Gross dust (sampling/weighing)
C.V.

0.14

0.05

0.10

0.22

0.09

0.05
Data Source

A

B

C

D

E

$E$

\section{Data Source References}

A. Analysis of data from $(31,32,33$, and 34 ) as discussed previously in this report.

B. NIOSH Engineering Branch estimate of typical calibrated promps capable of the range 1.5 to $3.0 \mathrm{lpm}$.

C. Conservative estimate by the authors. Recent work under NIOSH Contract CDC-99-74-75 have shown typical CVs (precision only) of 0.055 to 0.09 for charcoal tubes.

D. Reference (25).

E. NIOSH Engineering Branch estimate based on the use of promp in the flow range 1.5 to $3.0 \mathrm{lpm}$ and a collected mase of a least 1.0 milligram. 


\section{Full-Period Consecutive Samples Procedure}

The following procedure should be used to determine noncompliance with either a TWA, ceiling or excursion standard. It is used when several consecutive samples are taken for the entire time period for which the standard is defined. If the samples do not cover the entire time period of the standard, refer to the Partial Period Samples Procedure in the next section. The variability (standard deviation or coefficient of variation) of the sampling and analytical methods used to collect and analyze the samples must be well known from previous measurements. The statistical test given is a one-sided comparison-of-means test using the normal distribution at the $95 \%$ confidence level.

ONLY IF THE LCL OF THE MEAN OF THE CONSECUTIVE SAMPLES EXCEEDS THE STANDARD ARE WE 95\% CONFIDENT THAT THE TRUE AVERAGE CONCENTRATION EXCEEDS THE STANDARD AND THAT A CONDITION OF NONCOMPLIANCE EXISTS.

$$
L C L=\bar{x}-1.645 \sigma \bar{x}
$$

where $T_{i}=$ duration of $i$ th sample

$x_{i}=$ measurement of concentration in $i$ th sample

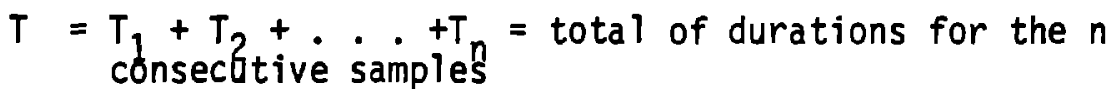

$\bar{x}=$ time weighted average of $n$ samples

$=(1 / T)\left(T_{1} x_{1}+T_{2} x_{2}+\ldots \cdot T_{n} x_{n}\right)$

$\sigma=$ standard deviation of sampling/analytical method which is well known from prior data

$$
\begin{aligned}
\sigma_{\bar{x}} & =(\sigma / T)\left(T_{1}^{2}+T_{2}^{2}+\ldots .+T_{n}^{2}\right)^{\frac{1}{2}} \\
& =\sigma /(n)^{\frac{3}{2}} \text { if } T_{1}=T_{2}=\ldots . \cdot=T_{n}
\end{aligned}
$$

If the coefficient of variation (C.V.) is known, $\sigma$ is computed from:

$$
\sigma=(C . V .) \text { (standard) }
$$

Figure 8 can be used to aid this calculation in the case of $n$ equalduration samples. Some coefficients of variation are available from Table 2. 
Partial-Period Consecutive Sample(s) Procedure

One or a series of consecutive samples collected over less than the period for which a standard is defined is referred to as a "partial period" sample(s). Since it is known with certainty that the concentration during the period not covered by the sample could not be less than zero, the 8 hour average standard is multipled by the following factor to obtain a conservative partial period standard. The LCL is then calculated as in the previous section and compared to the partial period standard.

$$
\text { Factor }=\frac{\text { (time period of the standard) }}{\text { (actual time of the sample(s)) }}
$$

For an 8-hour standard typical factors would be:

\begin{tabular}{cc} 
Total time of sample(s) & Factor \\
\hline 8.00 hours & 1.00 \\
7.75 & 1.032 \\
7.50 & 1.067 \\
7.25 & 1.103 \\
7.00 & 1.143 \\
6.75 & 1.185 \\
6.50 & 1.231 \\
6.25 & 1.280 \\
6.00 & 1.333
\end{tabular}

See Example \#2 for the use of the above technique. 
Grab Sample Data Analysis

As stated previously, if full period samples of industrial contaminant concentrations are available, the best method of modeling the uncertainties of the result is with a normal distribution. The appropriate statistical testing procedures were presented earlier in this report. However, when only a set of grab samples is available, the lognormal distribution best describes the uncertainties of the process. Draft versions of this report contained a procedure to compute a conservative lower confidence limit (LCL) on the average contaminant level from a number of grab samples. The method was conservative in that the confidence limits were rather wide since exact statistical theory was not available. However during the long developmental period of this report the results of a NIOSH contract became available. Partial results of this contract are presented as Appendix $A$ so that all data analysis basic procedures will be available to the reader in one report.

Appendix A presents a Grab Samples procedure for estimating the average concentration of a contaminant and making a decision on the level of the contaminant. The theory underlying this procedure was developed by systems Control, Inc. and reported in fuli in $(21,22)$. The main advantages of this procedure are:

1. It is contaminant-independent. Thus, it becomes possible to use only a single decision chart for every contaminant.

2. It is capable of both the Non-compliance Decision and the No Action Decision. Each of these decisions is subject to a predetermined probability of Type I or Type II error. A Type I error is said to occur if the non-compliance decision is wrongly asserted. A Type II error is said to occur if the no action decision is wrongly asserted.

3. The estimation and decision procedures are implemented via a simple and straightforward nomographic method. For estimation, the procedure yields the best estimate of the actual average contaminant level.

A minor disadvantage of the procedure is that the $L C L$ is not directly computed as in previous procedures. However it is felt the simplicity of the calculations required and the plotting of a single point on the decision chart far outweighs any advantages the direct calculation of an $\mathrm{LCL}$ would yield. Although the authors normally dislike a "black box" approach we feel most users of these procedures prefer simplicity and speed in reading a decision concerning sample results. 
Example \#1 for Consecutive Full-Period Samples Procedure

Hazardous concentrations of benzene were suspected in a plant. It was decided to use the personal charcoal tube sampling method with the low volume pump so that long-term (4-hour) samples could be taken. Several pumps were used and 4-hour samples were taken both in the morning and afternoon.

\begin{tabular}{|c|c|c|c|}
\hline Employee & Morning & Afternoon & TWA \\
\hline A & 12 ppm & 14 ppm & 13 ppm benzene \\
\hline B & 21 & 25 & 23 \\
\hline C & 25 & 21 & 23 \\
\hline D & 10 & 12 & 11 \\
\hline
\end{tabular}

The 1974 8-hour TWA standard for benzene is 10 ppm (29 CFR 1910.93).

First step

From Table 2 we obtain the C.V. for the charcoal tube method as 0.10 . To obtain $\sigma$ we multiply the standard $(10 \mathrm{ppm})$ by 0.10 for a $\sigma$ of $1.0 \mathrm{ppm}$. First test the two highest TWA's of $23 \mathrm{ppm}$ with the Consecutive Full-Period Samples Procedure.

\section{Second step}

The LCL on the mean of $23 \mathrm{ppm}$ is,

$$
\begin{aligned}
L C L & =23 \mathrm{ppm}-(1.645)(1.0 \mathrm{ppm}) /(2)^{\frac{1}{2}} \\
& =23-1.2=21.8 \mathrm{ppm}
\end{aligned}
$$

This could also have been done by reading the $1.2 \mathrm{ppm}$ from Fig 8 . For employee $A$ the $L C L$ is $(13-1.2)$ and for employee $D$ the $L C L$ is $(11-1.2=9.8)$.

\section{Third step}

For three of the four employees $(A, B, C)$ the $L C L$ on the means was higher than the 8-hour TWA Standard. We can conclude with $95 \%$ confidence that the true 8-hour TWA did exceed the standard for these employees and that a condition of noncompliance did exist. 
Example \#2 for Full-Period (Ceiling) Samples (Part a) and Partial Period Consecutive Samples Procedures (Part b)

The following data was obtained on one employee at one operation in an asbestos plarit:

Sample No. (i)

$\begin{array}{ccc}\frac{\text { Time Period }}{0848-0925} & \frac{\text { Duration } T_{i} \text { (min.) }}{37} & \frac{\text { Conc } x_{i}(\mathrm{f} / \mathrm{cc})}{17.5} \\ 0925-0952 & 27 & 15.5 \\ 0957-1039 & 42 & 8.0 \\ 1039-1105 & 26 & 17.5 \\ 1105-1137 & 32 & 19.0 \\ 1140-1149 & 9 & 32.0 \\ 1320-1341 & 21 & 10.0 \\ 1341-1425 & 44 & 6.8\end{array}$

The 1972 standards for asbestos are 1) $5 \mathrm{f} / \mathrm{cc}$ for 8-hour TWA and 2) $10 \mathrm{f} / \mathrm{cc}$ ceiling never to be exceeded. The samples represent a total sample time of 238 minutes out of a 440 minute exposure day (40 minutes for lunch).

Part a Ceiling Limit (Full Period Samples)

Note that OSHA recommends that samples taken for comparison to the ceiling standard be taken for a minimum of 15 minutes. Sample \#6, taken over only 9 minutes, is nevertheless included in this example for illustrative purposes.

\section{First Step}

First analyze all the samples except \#3,\#7, and \#8 for violation of the ceiling standard by the Full-Period Procedure. Calculate the $\sigma$ by multiplying the C.V. of 0.22 (Table 2) by the standard of $10 \mathrm{f} / \mathrm{cc}$. We obtain $\sigma=2.2 \mathrm{f} / \mathrm{cc}$. From Fig. 8 we see we need to subtract $3.6 \mathrm{f} / \mathrm{cc}$ from each sample to obta in the LCL for that sample. Alternatively, calculate $(1.645)(2.2)=3.62$ or 3.6 . 
Second step

For the five samples:

\begin{tabular}{|c|c|c|}
\hline Sample No. & Conc $(f / c c)$ & $\operatorname{LCL}(f / C C)$ \\
\hline 1 & 17.5 & 13.9 \\
\hline 2 & 15.5 & 11.9 \\
\hline 4 & 17.5 & 13.9 \\
\hline 5 & 19.0 & 15.4 \\
\hline 6 & 32.0 & 28.4 \\
\hline
\end{tabular}

Third step

For all five samples the $\mathrm{LCL}$ is greater than the ceiling standard of $10 \mathrm{f} / \mathrm{cc}$ and we are 95\% confident that the standard has been violated in each case.

Part b 8-Hour Average Limit (Partial Period Consecutive Samples)

Samples 1 through 8 have a TWA concentration of $15.8 \mathrm{f} / \mathrm{cc}$. This is the mean of 8 measurements that span an entire 238 minute time period.

First step

Calculate the partial period limit for the 238 minute period:

$$
\text { Limit }=(5 \mathrm{f} / \mathrm{cc})(480 / 238)=10.1 \mathrm{f} / \mathrm{cc}
$$

Second step

Calculate the $\mathrm{LCL}$ on the mean of the 8 consecutive measurements:

$$
\begin{aligned}
\bar{x} & =(3262.2 / 238)=13.7 \mathrm{f} / \mathrm{cc} \\
\sigma & =(\text { C.V. })(1 \text { imit })=(0.22)(10.1)=2.2 \\
\sigma_{\bar{x}} & =(2.2 / 238)(8,020)^{\frac{1}{2}}=0.83 \\
L C L & =\bar{x}-1.645 \bar{x} \\
& =13.7-(1.645)(0.83) \\
& =13.7-1.4=12.3
\end{aligned}
$$




\section{Third step}

The LCL $(12.3 \mathrm{f} / \mathrm{cc})$ on the mean of the 8 samples $(13.7 \mathrm{f} / \mathrm{cc})$ is greater than the limit for the 238 minute period $(10.1 \mathrm{f} / \mathrm{cc})$. Thus the employer is in violation of the 8-hour average standard and a citation should be issued. 
Example \#3 for Fu11-Period Consecutive Samples Procedure

Colorimetric detector tubes were used to sample for hydrogen sulfide. The standards for hydrogen sulfide are 1) $50 \mathrm{ppm}$ for a maximum duration of 10 minutes (once only if no other measurable exposure occurs) and 2)

$20 \mathrm{ppm}$ acceptable ceiling concentration for an 8-hour shift. Three

(3) detector tubes were used consecutively during each of three ten minute sampling periods during periods of expected peak exposure. The following results were obtained:

Period

$0905-0915 \mathrm{hrs}$.

$1110-1120$

$1320-1330$
Samples

$5,10,5 \mathrm{ppm}$

$35,55,15$

$20,25,30$
10 Min. Mean Conc.

\author{
$6.7 \mathrm{ppm}$ \\ 35.0 \\ 25.0
}

First step

Since the samples were obtained in a nonrandom fashion they should not be used for the determination of noncompliance with an 8-hour standard (this is academic since there was no 8-hour standard for hydrogen sulfide).

From Table 2 we obtain the coefficient of variation (C.V.) for colorimetric detector tubes as 0.14 .

Second step

Test the three values taken during the second period for noncompliance with the acceptable ceiling concentration standard of $20 \mathrm{ppm}$ with the Full-Period Consecutive Samples Procedufe. The mean of the three values is $35 \mathrm{ppm}$. The $\sigma$ is found by multiplying the C.V. of 0.14 by the $20 \mathrm{ppm}$ standard. We obtain a $\sigma$ of $2.8 \mathrm{ppm}$.

The LCL is:

$$
\begin{aligned}
L C L & =35 \mathrm{ppm}-(1.645)(2.8 \mathrm{ppm}) /(3)^{\frac{1}{2}} \\
& =32.3 \mathrm{ppm} .
\end{aligned}
$$

(A7 ternatively, $2.7 \mathrm{ppm}$ could have been read from Figure 8 and subtracted from 35 ppm.)

Fourth step

Since the LCL of the mean value of the three tubes (32.2 ppm) exceeds the standard (20 ppm), we can conclude with $95 \%$ confidence that the true average concentration during the 10-minute period did exceed the ceiling standard. A citation could be issued because a condition of noncompliance exists. 


\section{REFERENCES}

1. Roach, S.A.: "Testing Compliance with the ACGIH Threshold Limit Values for Respirable Dusts Evaluated by Count," Trans. ACGIH, 27-39(1966).

2. Roach, S.A.: "A More Rational Basis for Air Sampling Programs, AIHA J., 27, 1-12 (1966).

3. Roach, S.A., Baier, E.J., Ayer, H.E., and R.L. Harris: "Testing Compliance with Threshold Limit Values for Respirable Dusts", AIHA J, 28, 543-550 (1967).

4. Kerr, G.W.: "Use of Statistical Methodology in Environmental Monitoring", AIHA J, 23, 75-82 (1962).

5. Larsen, R.I.: "A Method for Determining Source Reduction Required to Meet Quality Standards", JAPCA,11, 71 (1961).

6. Larsen, R.I.: "A New Mathematical Model of Air Pollutant Concentration Averaging Time and Frequency", JAPCA, 19, 24 (1969).

7. Phinney, D.E. and J.E. Newman: "The Precision Associated with the Sampling Frequencies of Total Particulate at Indianapolis, Indiana", JAPCA, 22, 692-695 (1972).

8. Larsen, R.I.: "A Mathematical Model for Relating Air Quality Measurements to Air Quality Standards", AP-89, Environmental Protection Agency, U.S. Gov't Printing Office (1971).

9. Breslin, A.J., Ong, L., Glauberman, H., George, A.C., and P. LeClare: "The Accuracy of Dust Exposure Estimates Obtained from Conventional Air Sampling", AIHA J, 28, 56-61 (1967).

10. Sherwood, R.J.: "On the Interpretation of Air Sampling for Radioactive Particles", AIHA J, 27, 98-109 (1966).

11. Sherwood, R.J.: "The Monitoring of Benzene Exposure by Air Sampling". AIHA J, 32, 840-846 (1971).

12. Jones, A.R. and R.S. Brief: "Evaluating Benzene Exposures", AIHA J, 32, 610-613, (1971).

13. Gale, H.J.: "The Lognormal Distribution and Some Examples of Its Application in the Field of Radiation Protection", Atomic Energy Research Establishment Report AERE-R 4736, Her Majesty's Stationery Office (1965). 
14. Gale, H.J.: "Some Examples of the Application of the Lognormal Distribution in Radiation Protection", Ann. Occup. Hyg., 10, 39-45 (1967)

15. Coenen, W.: "The Confidence Limits for the Mean Values of Dust Concentration", Staub, 26, 39-45 (Engl. Translation) (May 1966).

16. Coenen, W.: "Measurement Assessment of the Concentration of HealthImparing, Especially Silicogenic Dusts at Work Places of Surface Industries", Staub, 31, 16-23 (Engl. Transiation) (December 1971).

17. Hounam, R.F.: "An Application of the Log-Normal Distribution to Some Air Sampling Results and Reconmendations on the Interpretation of Air Sampling Data". Atomic Energy Research Establishment Report AERE-M 1469, Her Majesty"s Stationary Office (1965).

18. Juda, J. and K. Budzinski: "Fehler bei der Bestimmung der mittleren Staubkonzentration als Funktion der Anzahl der Einzelmessungen" (Errors in Determining the Mean Dust Concentration as a Function of the Number of Individual Measurements), Staub, 24, 283-287, (August 1964).

19. Juda, J. and K. Budzinski: "Determining the Tolerance Range of the Mean Value of Dust Concentration", Staub, 27, 12-16 (Engl. Translation) (April 1967).

20. LeClare, P.L., Breslin, A.J., and L. Ong: "Factors Affecting the Accuracy of Average Dust Concentration Mea surements", AIHA J, 30, 386-393 (1969).

21. Bar-Shalom, Y., Segaill, A., Budenaers, D., and R.B. Sha inker: "Statistical Theory for Sampling of Time-Varying Industrial Atmospheric Contaminant Levels," Systems Control, Inc., Final Report for NIOSH Contract HSM 99-73-78, Palo Alto, CA, June 1974.

22. Budenaers, D., Bar-Shalom, Y., Segall, A., and R.B. Schainker: "Handbook for Decisions on Industrial Atmospheric Contaminant Exposure Levels," Systems Control, Inc., Final Field Handbook for NIOSH Contract HSM 99-73-78, Palo Al to, CA, June 1974.

23. Leidel, N.A.: "Statistics in Compliance", presented at the 1974 American Industrial Hygiene Conference, Miami Beach, Florida, 14 May 74.

24. Leide1, N.A.: "Optimum Sampling Times for Airborne Asbestos Fibers", USPHS, NIOSH TR-82 (1973). 
25. Leidel, N.A., Bayer, S. G., and R.D. Zumwalde: "USPHS/NIOSH Membrane Filter Method for Evaluating Airborne Asbestos Fibers", USPHS, NIOSH Tr-84 (1973).

26. Larsen, R.I., C.E. Zimmer, D.A. Lynn, and K. G. Blemel: "Analyzing Air Pollutant Concentration and Dosage Data", JAPCA, 17, 85-93 (1967).

27. Saltzman, B.E.: "Significance of Sampling Time in Air Monitoring", JAPCA, 20, 660-665 (1970).

28. Natrella, M.G.: "Experimental Statistics", NBS Handbook \#91, U.S. Gov't Printing Office (1963).

29. Federal Register, 39 , 23540-23583 (27 June 74).

30. "NIOSH Certified Personal Protective Equipment", NIOSH Publication 75-119, July 74 (with Sept. 74 and Jan. 75 Supplements).

31. Johnson, B.A.: The Evaluation of Gas Detector Tube Systems: Hydrogen Sulfide, USPHS/NIOSH RR-18 (1972).

32. Johnson, B.A., and Roper, P.: The Evaluation of Gas Detector Tube Systems: Chlorine, USPHS/NIOSH RR-19 (1972).

33. Johnson, B.A.: The Evaluation of Gas Detector Tube Systems: Ozone, USPHS/NIOSH RR-21 (1972).

34. Roper, P.: The Evaluation of Gas Detector Tube System: Trichloroethylene, USPHS/NIOSH RR-22 (1972).

Notes on availability of references.

a) Refierences 21 and 22 will be available from NIOSH as NTRSH Technical Report 75 - 147, a combined publication.

b) References 24 and 25 are to be reprinted by NIOSH as a combined publication under the title listed for refierence 25. 


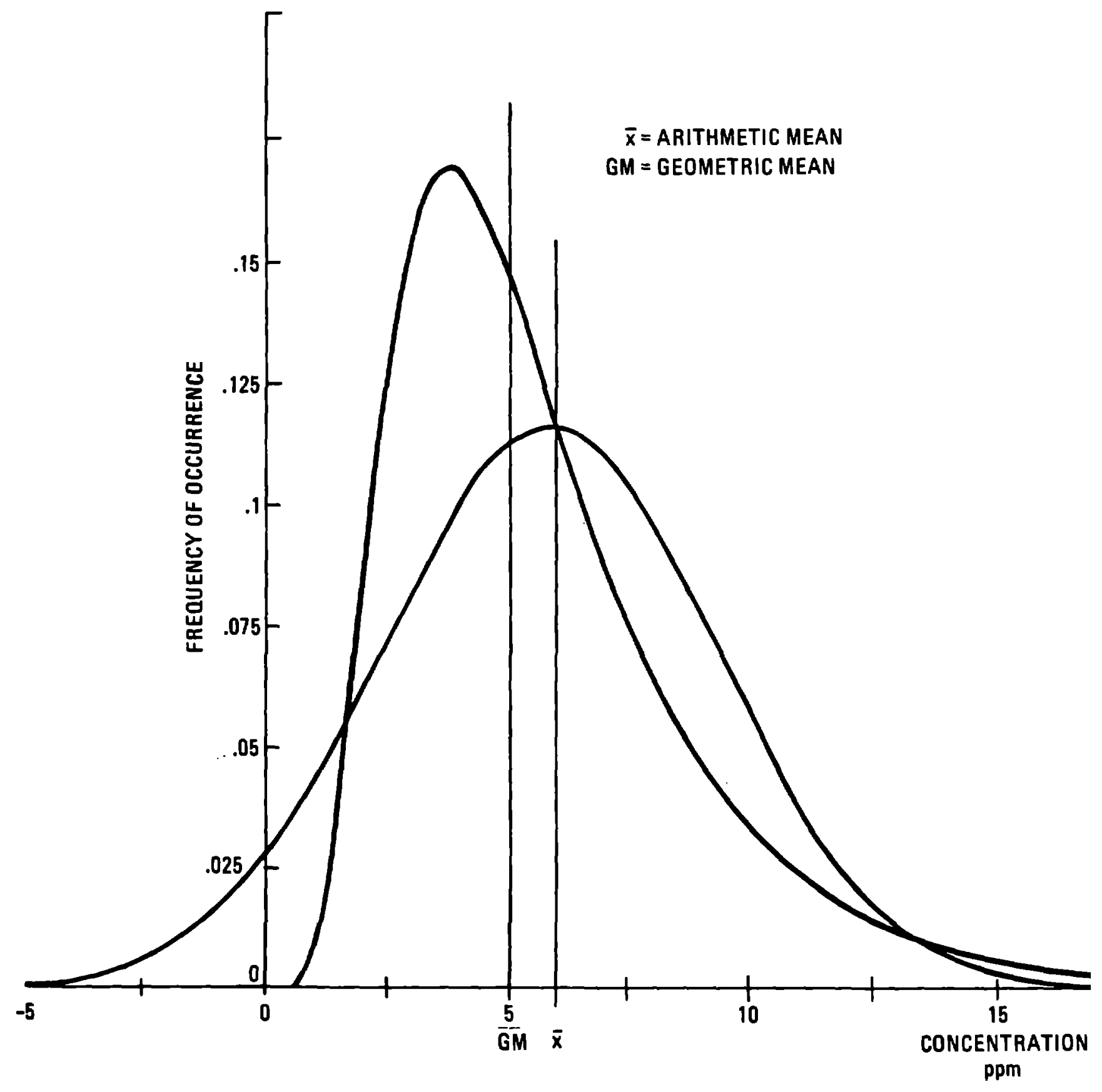

Figure 1 - Log normal and normal distributions with the same arithmetic mean and standard deviation.

Preceding page blank 


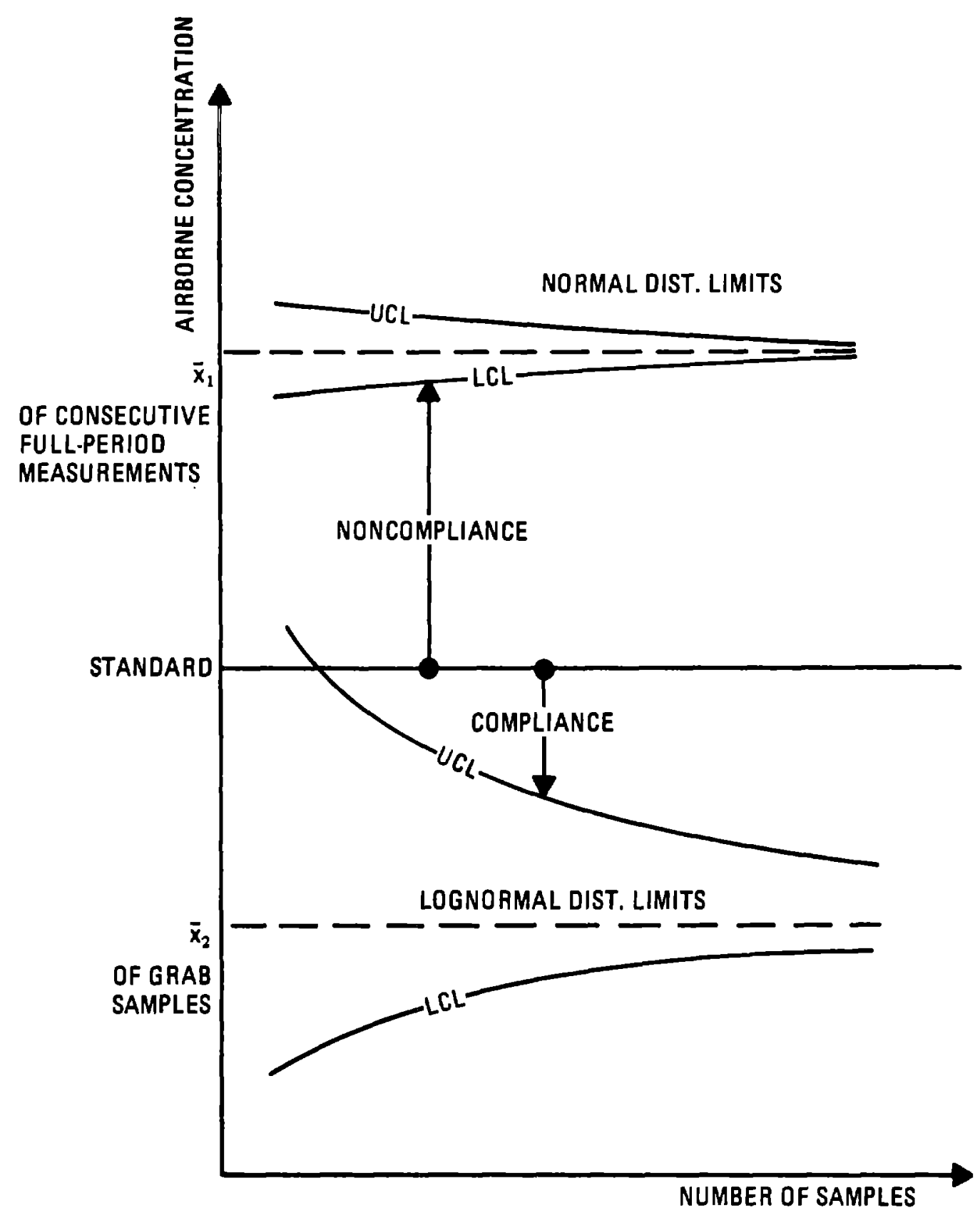

Figure 2 - Compliance and noncompliance situations for two tvpes of sampling strategies. 


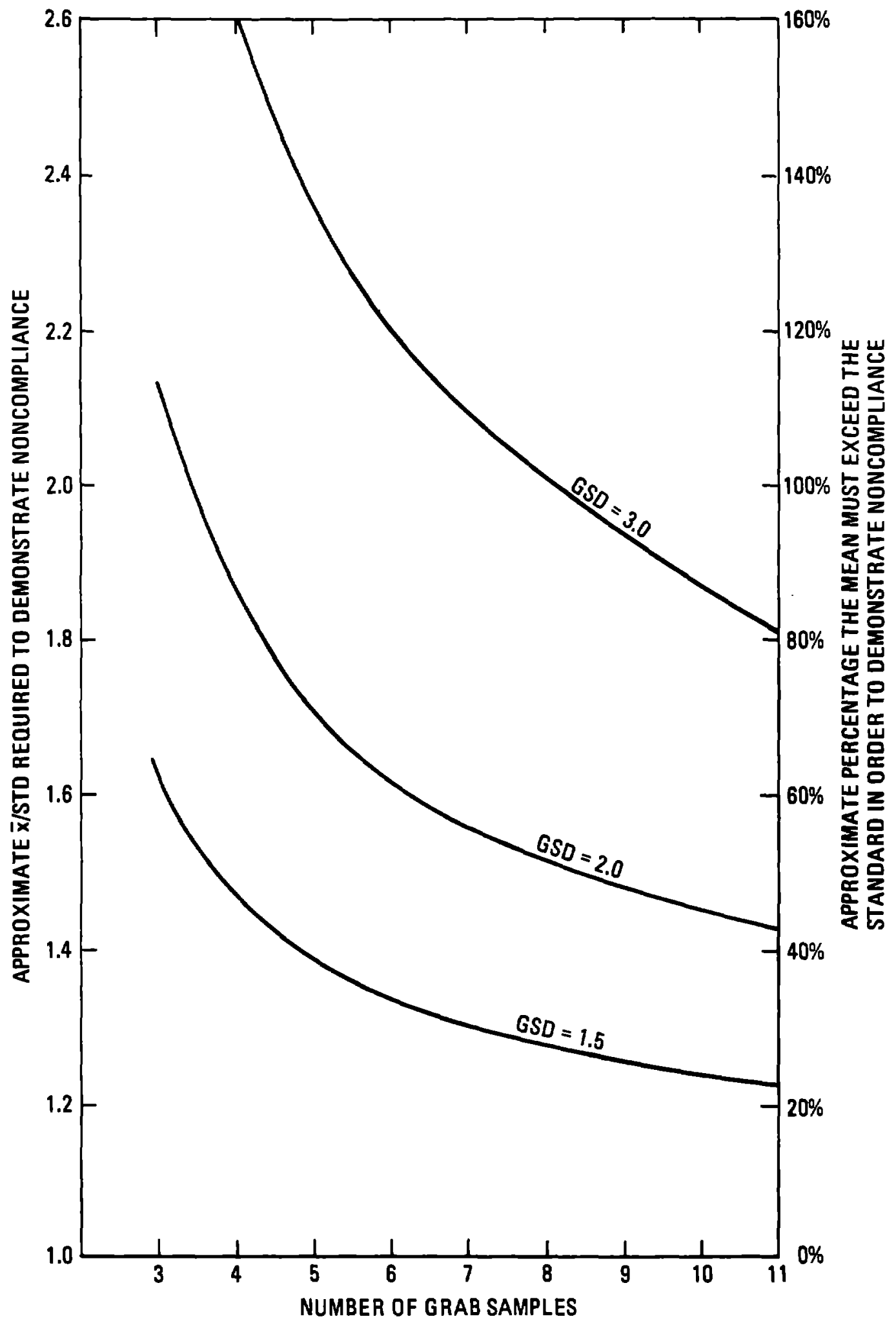

Figure 3 - Effect of small grab sample sizes on requirements for demonstration of noncompliance. Three different data geometric standard deviations (GSD) are shown which reflect the amount of variability in the environment. 


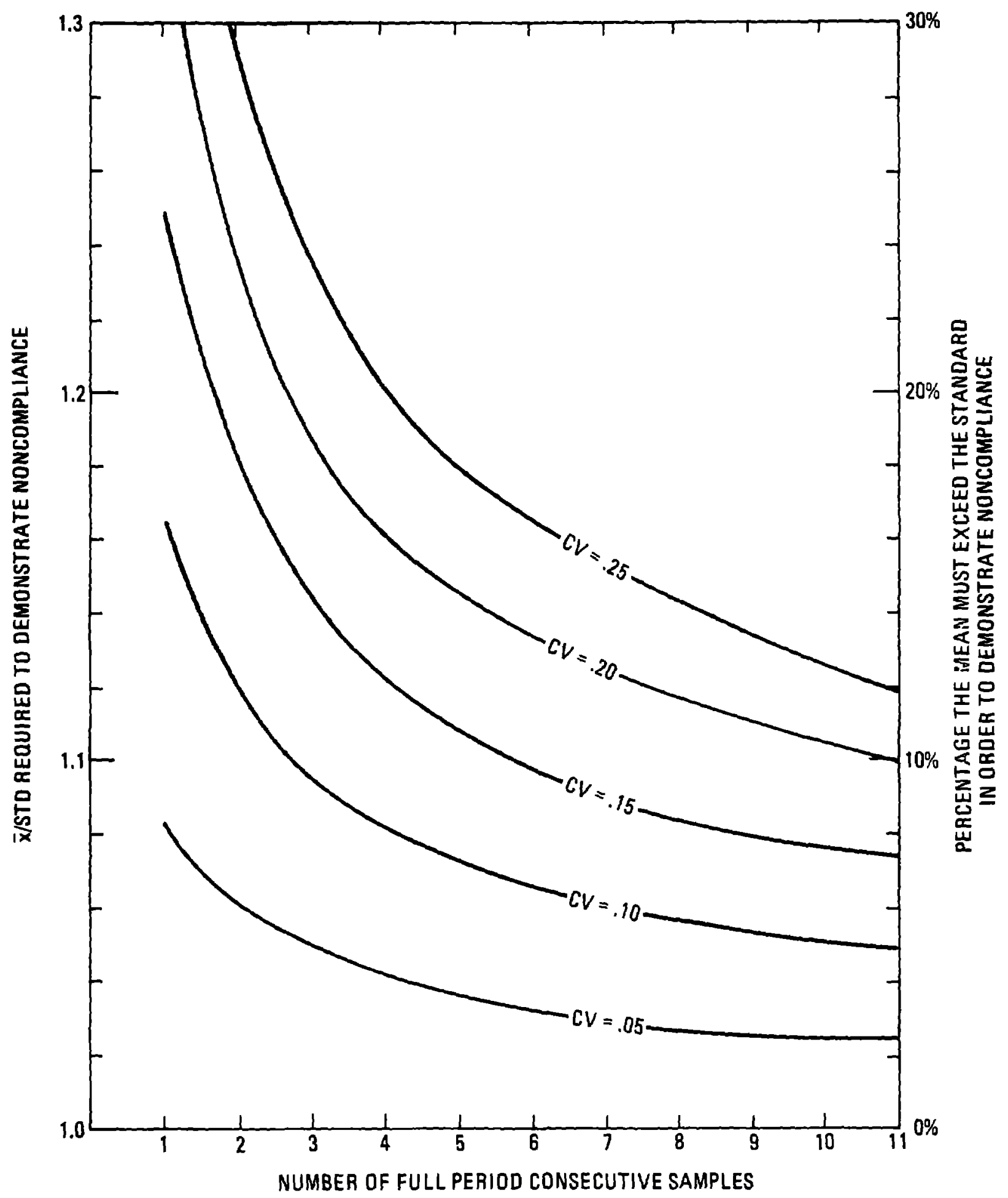

Figure 4 - Effect of Full Period Consecutive Samole size on requirements for demonstration of noncompliance. 


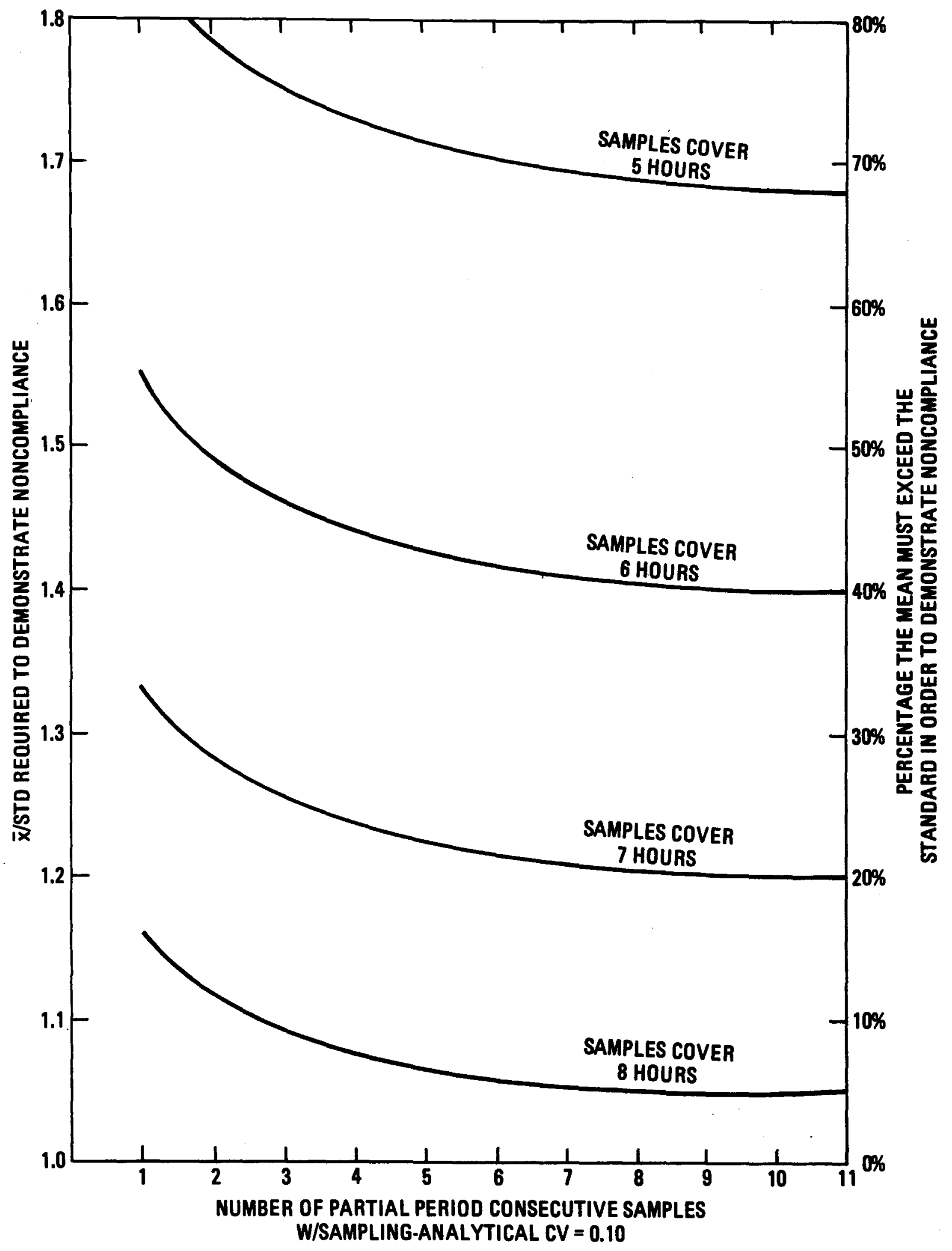

Figure 5 - Effect of Partial Period Consecutive Sample size and total time covered by all samples on requirements for demonstration of noncombliance. 
TABLE A-36. SHORT TABLE OF RANDOM NUMBERS

$\begin{array}{lllllllllllllllllllllllll}46 & 96 & 85 & 77 & 27 & 92 & 86 & 26 & 45 & 21 & 89 & 91 & 71 & 42 & 64 & 64 & 53 & 22 & 75 & 81 & 74 & 91 & 48 & 46 & 18\end{array}$ $\begin{array}{lllllllllllllllllllllllll}44 & 19 & 15 & 32 & 63 & 55 & 87 & 77 & 33 & 29 & 45 & 00 & 31 & 34 & 84 & 0.5 & 72 & 90 & 4 & 27 & 78 & 22 & 07 & 62 & 17\end{array}$

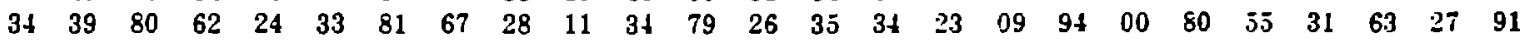
$\begin{array}{lllllllllllllllllllllllll}74 & 97 & 80 & 30 & 65 & 07 & 71 & 30 & 01 & 84 & 47 & 45 & 89 & 70 & 74 & 13 & 04 & 90 & 51 & 27 & 61 & 34 & 63 & 87 & 44\end{array}$ $\begin{array}{lllllllllllllllllllllllll}22 & 14 & 61 & 60 & 86 & 38 & 33 & 71 & 13 & 33 & 72 & 08 & 16 & 13 & 50 & 56 & 48 & 51 & 29 & 48 & 30 & 93 & 45 & 66 & 29\end{array}$

$\begin{array}{lllllllllllllllllllllllll}40 & 03 & 96 & 40 & 03 & 47 & 24 & 60 & 09 & 21 & 21 & 18 & 00 & 05 & 86 & 52 & 85 & 40 & 73 & 73 & 57 & 68 & 36 & 33 & 91\end{array}$ $\begin{array}{lllllllllllllllllllllllll}52 & 33 & 76 & 44 & 56 & 15 & 47 & 75 & 78 & 73 & 78 & 19 & 87 & 06 & 98 & 47 & 48 & 02 & 62 & 03 & 42 & 05 & 32 & 55 & 02\end{array}$ $\begin{array}{lllllllllllllllllllllllll}37 & 59 & 20 & 40 & 93 & 17 & 82 & 24 & 19 & 90 & 80 & 87 & 32 & 74 & 59 & 84 & 24 & 49 & 79 & 17 & 23 & 75 & 83 & 42 & 00\end{array}$ $\begin{array}{lllllllllllllllllllllllll}11 & 02 & 55 & 57 & 48 & 84 & 74 & 36 & 22 & 67 & 19 & 20 & 15 & 92 & 53 & 37 & 13 & 75 & 54 & 89 & 56 & 73 & 23 & 39 & 07\end{array}$ $\begin{array}{lllllllllllllllllllllllll}10 & 33 & 79 & 26 & 34 & 54 & 71 & 33 & 89 & 74 & 68 & 48 & 23 & 17 & 49 & 18 & 81 & 05 & 52 & 85 & 70 & 05 & 73 & 11 & 17\end{array}$

$\begin{array}{lllllllllllllllllllllllll}-67 & 59 & 28 & 25 & 47 & 89 & 11 & 65 & 65 & 20 & 42 & 23 & 96 & 41 & 64 & 20 & 30 & 89 & 87 & 64 & 37 & 93 & 36 & 96 & 35\end{array}$ $\begin{array}{lllllllllllllllllllllllll}93 & 50 & 75 & 20 & 09 & 18 & 54 & 34 & 68 & 02 & 54 & 87 & 23 & 05 & 43 & 36 & 98 & 29 & 97 & 93 & 87 & 08 & 30 & 92 & 98\end{array}$ (24) $\begin{array}{llllllllllllllllllllllll}43 & 23 & 72 & 80 & 64 & 34 & 27 & 23 & 46 & 15 & 36 & 10 & 63 & 21 & 59 & 69 & 76 & 02 & 62 & 31 & 62 & 47 & 60 & 34\end{array}$ $\begin{array}{lllllllllllllllllllllllll}39 & 91 & 63 & 18 & 38 & 27 & 10 & 78 & 88 & 84 & 42 & 32 & 00 & 97 & 92 & 00 & 04 & 94 & 50 & 05 & 75 & 82 & 70 & 80 & 35\end{array}$ $\begin{array}{lllllllllllllllllllllllll}74 & 62 & 19 & 67 & 54 & 18 & 28 & 92 & 33 & 69 & 98 & 96 & 74 & 35 & 72 & 11 & 68 & 25 & 08 & 95 & 31 & 79 & 11 & 79 & 54\end{array}$

$\begin{array}{lllllllllllllllllllllllll}91 & 03 & 35 & 60 & 81 & 16 & 61 & 97 & 25 & 14 & 78 & 21 & 22 & 05 & 25 & 47 & 26 & 37 & 80 & 39 & 19 & 06 & 41 & 02 & 00\end{array}$ $\begin{array}{lllllllllllllllllllllllll}42 & 57 & 66 & 76 & 72 & 91 & 03 & 63 & 48 & 46 & 44 & 01 & 33 & 53 & 62 & 28 & 30 & 59 & 55 & 05 & 02 & 16 & 13 & 17 & 54\end{array}$ (06) $\begin{array}{llllllllllllllllllllllll}36 & 63 & 06 & 15 & 03 & 72 & 38 & 01 & 58 & 25 & 37 & 66 & 48 & 56 & 19 & 56 & 41 & 29 & 28 & 76 & 49 & 74 & 39 & 50\end{array}$ $\begin{array}{lllllllllllllllllllllllll}92 & 70 & 96 & 70 & 89 & 80 & 87 & 1+ & 25 & 49 & 25 & 94 & 62 & 78 & 26 & 15 & \$ 1 & 39 & 48 & 75 & 64 & 69 & 61 & 06 & 38\end{array}$ $\begin{array}{lllllllllllllllllllllllll}91 & 08 & 88 & 53 & 52 & 13 & 04 & 82 & 23 & 00 & 26 & 36 & 47 & 44 & 04 & 08 & 54 & 80 & 07 & 44 & 76 & 51 & 52 & 41 & 59\end{array}$

$\begin{array}{lllllllllllllllllllllllll}68 & 85 & 97 & 74 & 47 & 53 & 90 & 05 & 90 & 84 & 87 & 48 & 25 & 01 & 11 & 0.5 & 45 & 11 & 4.3 & 15 & 60 & 40 & 31 & 84 & 59\end{array}$ $\begin{array}{lllllllllllllllllllllllll}59 & 54 & 13 & 09 & 13 & 80 & 42 & 29 & 63 & 03 & 24 & 64 & 12 & 43 & 25 & 10 & 01 & 5.5 & 62 & 07 & 79 & 83 & 05 & 59 & 61\end{array}$ $\begin{array}{lllllllllllllllllllllllll}39 & 18 & 32 & 69 & 33 & 46 & 58 & 19 & 34 & 03 & 59 & 28 & 97 & 31 & 02 & 65 & 47 & 47 & 70 & 39 & 74 & 17 & 30 & 2.2 & 65\end{array}$ $\begin{array}{lllllllllllllllllllllllll}67 & 43 & 31 & 09 & 12 & 60 & 19 & 57 & 63 & 78 & 11 & 50 & 10 & 97 & 15 & 70 & 04 & 89 & 81 & 78 & 54 & 84 & 87 & 83 & 42\end{array}$ $\begin{array}{lllllllllllllllllllllllll}61 & 75 & 37 & 19 & 56 & 90 & 75 & 39 & 03 & 56 & 49 & 92 & 72 & 95 & 27 & 52 & 5 i & 47 & 12 & 52 & 54 & 62 & 43 & 23 & 13\end{array}$

$\begin{array}{lllllllllllllllllllllllll}78 & 10 & 91 & 11 & 00 & 63 & 19 & 63 & 74 & 58 & 69 & 03 & 51 & 38 & 60 & 36 & 53 & 56 & 77 & 06 & 69 & 03 & 89 & 91 & 24\end{array}$ $\begin{array}{lllllllllllllllllllllllll}93 & 23 & 71 & 58 & 09 & 78 & 08 & 03 & 07 & 71 & 79 & 32 & 25 & 19 & 61 & 04 & 40 & 33 & 12 & 06 & 78 & 91 & 97 & 88 & 95\end{array}$ $\begin{array}{lllllllllllllllllllllllll}37 & 55 & 48 & 82 & 63 & 89 & 92 & 59 & 14 & 72 & 19 & 17 & 22 & 51 & 90 & 20 & 03 & 64 & 96 & 60 & 48 & 01 & 95 & 44 & 84\end{array}$

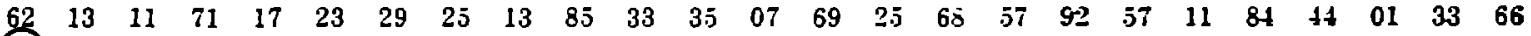

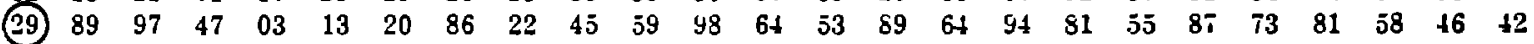

(16) $\begin{array}{llllllllllllllllllllllll}94 & 85 & 82 & 89 & 07 & 17 & 30 & 29 & 89 & 89 & 80 & 98 & 36 & 25 & 36 & 53 & 02 & 49 & 14 & 34 & 03 & 52 & 09 & 20\end{array}$ (04) $\begin{array}{llllllllllllllllllllllll}93 & 10 & 59 & 75 & 12 & 98 & 84 & 60 & 93 & 68 & 16 & 87 & 60 & 11 & 50 & 46 & 56 & 58 & 45 & 88 & 72 & 50 & 46 & 11\end{array}$ $\begin{array}{lllllllllllllllllllllllll}95 & 71 & 43 & 68 & 97 & 18 & 85 & 17 & 13 & 08 & 00 & 50 & 77 & 50 & 46 & 92 & 45 & 26 & 97 & 21 & 48 & 22 & 23 & 08 & 32\end{array}$ $\begin{array}{lllllllllllllllllllllllll}86 & 05 & 39 & 14 & 35 & 48 & 68 & 18 & 36 & 57 & 09 & 62 & 40 & 28 & 87 & 08 & 7 t & 79 & 91 & 08 & 27 & 12 & 43 & 32 & 03\end{array}$ $\begin{array}{lllllllllllllllllllllllll}59 & 30 & 60 & 10 & 41 & 31 & 00 & 69 & 63 & 77 & 01 & 89 & 94 & 60 & 19 & 0.2 & 70 & 88 & 72 & 33 & 38 & 88 & 20 & 60 & 86\end{array}$

$\begin{array}{lllllllllllllllllllllllll}05 & 45 & 35 & 40 & 54 & 03 & 98 & 96 & 76 & 27 & 77 & 84 & 80 & 08 & 64 & 60 & 44 & 34 & 54 & 24 & 85 & 20 & 85 & 77 & 32\end{array}$ $\begin{array}{lllllllllllllllllllllllll}71 & 85 & 17 & 74 & 66 & 27 & 85 & 19 & 55 & 56 & 51 & 36 & 48 & 92 & 32 & 44 & 40 & 47 & 10 & 38 & 22 & 52 & 42 & 29 & 96\end{array}$ $\begin{array}{lllllllllllllllllllllllll}80 & 20 & 32 & 80 & 98 & 00 & 40 & 92 & 57 & 51 & 52 & 83 & 14 & 55 & 31 & 99 & 73 & 23 & 40 & 07 & 64 & 54 & 44 & 99 & 21\end{array}$ $\begin{array}{lllllllllllllllllllllllll}13 & 50 & 78 & 02 & 73 & 39 & 66 & 82 & 01 & 28 & 67 & 51 & 75 & 66 & 33 & 97 & 47 & 58 & 42 & 44 & 88 & 09 & 28 & 58 & 06\end{array}$ $\begin{array}{lllllllllllllllllllllllll}67 & 92 & 65 & 41 & 45 & 36 & 77 & 96 & 46 & 21 & 14 & 39 & 56 & 36 & 70 & 15 & 74 & 43 & 62 & 69 & 82 & 30 & 77 & 28 & 77\end{array}$

$\begin{array}{lllllllllllllllllllllllll}72 & 56 & 73 & 44 & 26 & 04 & 62 & 81 & 15 & 35 & 79 & 26 & 99 & 57 & 23 & 2.2 & 25 & 94 & 80 & 62 & 95 & 48 & 98 & 23 & 86\end{array}$ $\begin{array}{lllllllllllllllllllllllll}28 & 86 & 85 & 64 & 94 & 11 & 58 & 78 & 45 & 36 & 34 & 45 & 91 & 38 & 51 & 10 & 68 & 36 & 87 & 81 & 16 & 77 & 30 & 19 & 36\end{array}$ $\begin{array}{lllllllllllllllllllllllll}69 & 57 & 40 & 80 & 44 & 94 & 60 & 82 & 94 & 93 & 98 & 01 & 48 & 50 & 57 & 69 & 60 & 77 & 69 & 60 & 74 & 22 & 05 & 77 & 17\end{array}$ $\begin{array}{lllllllllllllllllllllllll}71 & 20 & 03 & 30 & 79 & 25 & 74 & 17 & 78 & 34 & 54 & 45 & 04 & 77 & 42 & 59 & 75 & 73 & 64 & 99 & 37 & 03 & 18 & 03 & 36\end{array}$ $\begin{array}{lllllllllllllllllllllllll}89 & 98 & 55 & 98 & 22 & 45 & 12 & 49 & 82 & 71 & 57 & 33 & 28 & 69 & 50 & 59 & 15 & 09 & 25 & 79 & 39 & +2 & 84 & 18 & 70\end{array}$

$\begin{array}{lllllllllllllllllllllllll}58 & 74 & 82 & 81 & 14 & 02 & 01 & 05 & 77 & 94 & 65 & 57 & 70 & 39 & 42 & \text { is } & 56 & 84 & 31 & 59 & 13 & 70 & 41 & \text { it } & 60\end{array}$ $\begin{array}{lllllllllllllllllllllllll}50 & 54 & 73 & 81 & 91 & 07 & 81 & 26 & 25 & 45 & 49 & 61 & 22 & 88 & 41 & 20 & 00 & 15 & 59 & 93 & 51 & 60 & 65 & 65 & 63\end{array}$ $\begin{array}{lllllllllllllllllllllllll}49 & 33 & 72 & 90 & 10 & 20 & 65 & 28 & 44 & 63 & 95 & 86 & 75 & 78 & 69 & 24 & 41 & 65 & 55 & 10 & 34 & 10 & 32 & 00 & 93\end{array}$ $\begin{array}{lllllllllllllllllllllllll}11 & 85 & 01 & 43 & 65 & 0.2 & 85 & 69 & 56 & 88 & 34 & 29 & 64 & 3.5 & t 5 & 1.5 & 70 & 11 & 7 i & 53 & 01 & 34 & 82 & 91 & 04\end{array}$ $\begin{array}{lllllllllllllllllllllllll}34 & 22 & 46 & 41 & 84 & 74 & 27 & 02 & 57 & 77 & 47 & 93 & 72 & 02 & 95 & 63 & 75 & 74 & 69 & 69 & 61 & 34 & 31 & 92 & 13\end{array}$

Adapted with permission from A Million Rardom Digits by The Rand Corporation. Copyrigbt 1955. The Free Preso.

Fig. 6 - First page of Table A-36 in Natrella (28). 


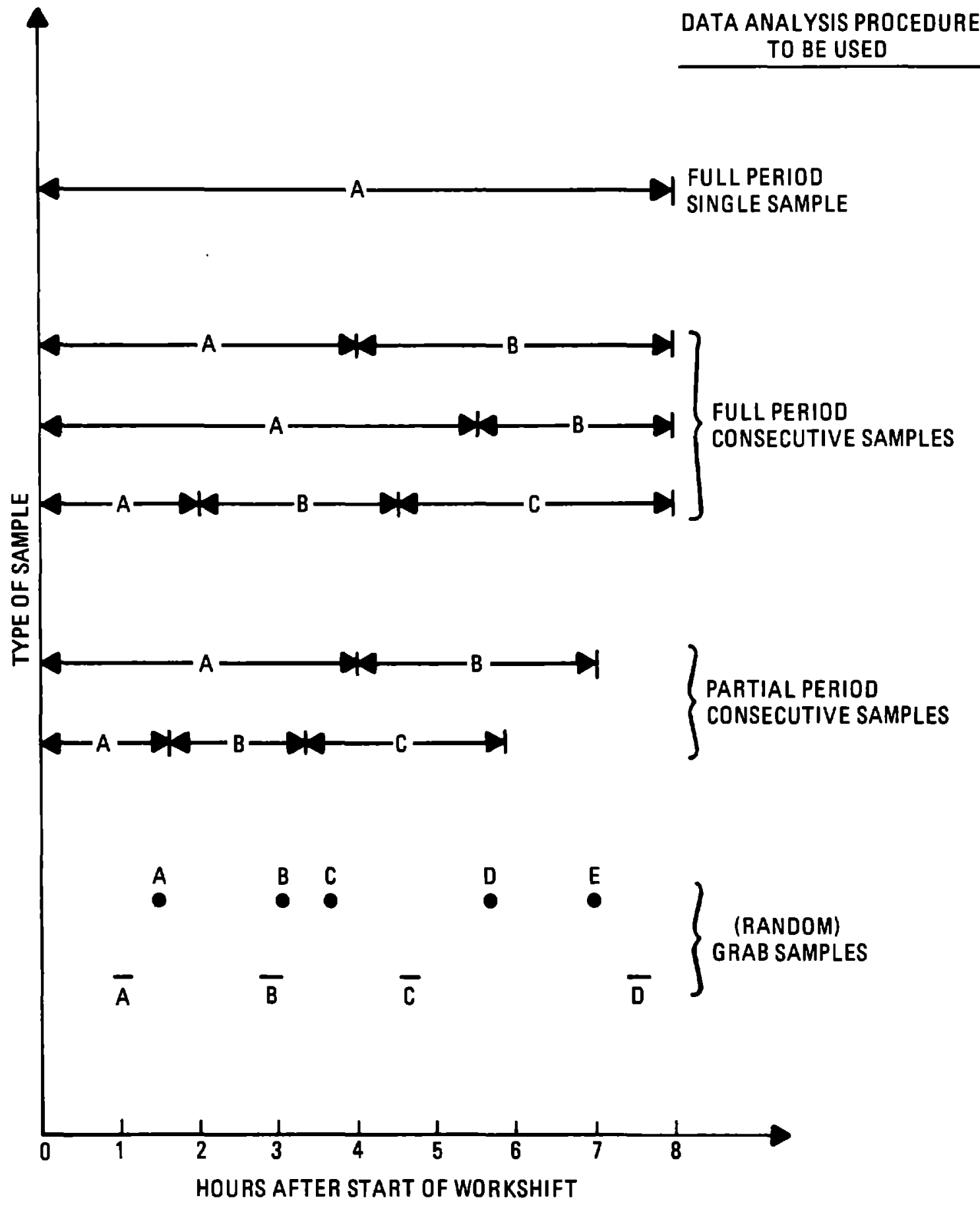

Figure 7 - Reference chart of data analysis procedures to use for an 8-hour average exposure standard. 


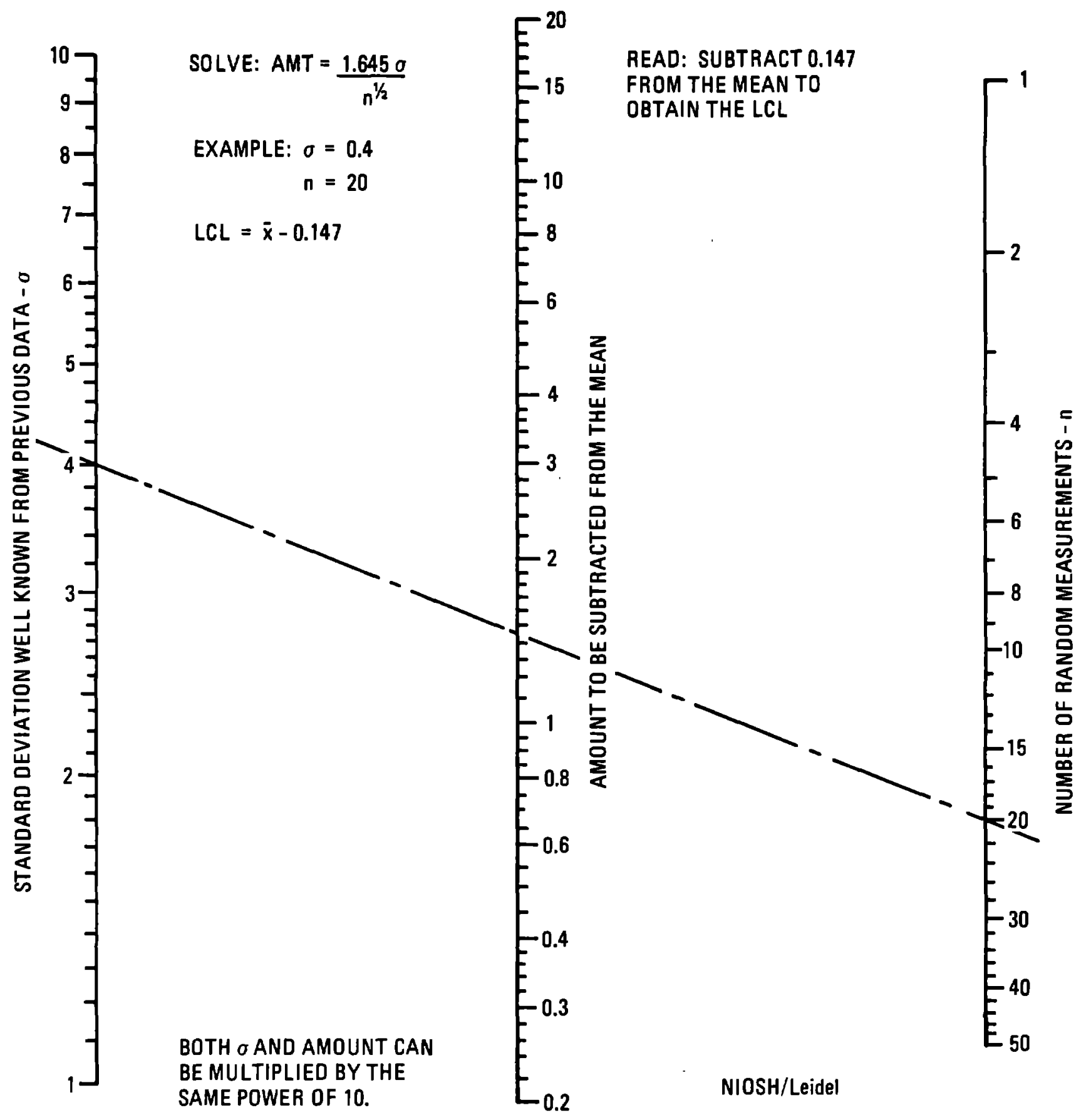

Figure 8 - Nomogram for Full Period or Partial Period procedures using a well known standard deviation. 


\section{APPENDIX A - GRAB SAMPLES PROCEDURE}

\subsection{DEFINITIONS}

This section contains a Definition of Terms and Notations used in this Appendix. Section 0.1 contains the Definition of Terms. The term or phrase being defined is underlined. Section 0.2 contains a definition of all mathematical notations used in this Appendix.

\subsection{DEFINITION OF TERMS}

Average concentration: Arithmetic mean of concentration over an 8-hour period.

Federal Standard (for 8-hour exposures): The highest level of average concentration to which a worker can be exposed (29 CFR 1910.93).

Relative.Concentration: Measured concentration divided by the Federal Standard.

A non-compliance Decision: A decision made with a given maximum low probability of error that a worker's contaminant exposure level exceeds the Federal Standard.

A No Action Decision: A decision made with a given maximum low probability of error that a worker's contaminant exposure does not exceed the Federal Standard.

No Decision: A decision that neither compliance nor non-compliance can be asserted with sufficiently low probabilities of making the respective incorrect decisions.

Stationary (time-invariant) Data: A set of data for which the mean and variance do not change with time.

Normally Distributed Variable: A variable which is said to be normally distributed has fluctuations which have a bell-shaped frequency distribution which is characterized fully by the mean and standard deviation.

Lognormally Distributed Variable: A variable is said to be lognormally distributed if the logarithm of the variable is normally distributed. 


\subsection{NOTATIONS}

STD: Federal Standard such as 29 CFR 1910.93

$M$ : Average concentration

$\hat{M}$ : Best estimate of the average concentration

$n$ : Number of concentration samples

s : Sample standard deviation

$t_{i}$ : Midpoints of sampling periods during which the concentrations $x_{i}$ are obtained

$x_{i}$ : Measurements of the concentrations

$x_{i}$ : Ratio between measurements and the Federal Standard

$y_{i}$ : Logarithm (base 10) of $x_{i}$

$\bar{y}$ : Sample Mean of $y_{i}$ 
1. INTRODUCTION

This Appendix presents an easy to follow procedure for making decisions regarding the average of a time varying industrial contaminant exposure level. By using this Appendix it will be possible to make statistical decisions as to whether or not a particular contaminant level exceeds the exposure standards set forth by OSHA regulations 29 CFR 1910.93. A list of definitions of terms and concepts used in this handbook is presented in Section 0. The procedures in this Appendix will allow one to make one of the following three decisions regarding a worker's contaminant exposure level:

- Non-compliance

- No Action

- No Decision

By "Non-compliance" it is meant that the decision has been reached at a given high confidence level that the worker's contaminant exposure level exceeds the Federal Standard. By "No Action" it is meant that the decision has been reached with a given high confidence level that the worker's contaminant exposure level does not exceed the standard. Finally, by the "No Decision" choice it is meant that neither of the above choices can be asserted with a sufficientiy high confidence level.

In addition to the three-way decision procedure described above, this handbook will provide a nomographic method of determining the best estimate of the actual average level of contaminant.

The decision and estimation procedures described in this handbook cover the case where the contaminant data is a set of grab samples from a timevarying industrial environment. A lognormal distribution is assumed for the variability of individual grab samples taken at random intervals.

The step-by-step procedures to be followed in making decisions regarding contaminant exposure level and in obtaining estimates of average contaminant level are described in Section 2. Examples of procedure are provided in Section 3.

The suggested method of using this procedure is as follows:

Review Section 2 to gain an overview of the methodology without undue concern about understanding all the procedural details.

Then, work through the examples in Section 3, to obtain insight into the methodology presented in Section 3.

If necessary, review Section 2 to solidify the procedure. 


\section{DESCRIPTION OF THE PROCEDURE}

This section describes the procedure for estimating and making decisions on the average concentration of an industrial contaminant. An outline of the procedure is presented in Section 2.1. A detailed description of each of the steps in the procedure is presented in Section 2.2. A collection of examples on the use of the procedure is presented in Section 3.

\subsection{OUTLINE OF PROCEDURE}

The procedure is divided into the following six steps. The interrelationship between the steps is illustrated in the flow diagram in Figure 1.

Step 1: Collect data, then proceed to Step 2.

Step 2: Check whether a decision can be reached immediately; if not, proceed to Step 3.

Step 3: Preprocess the data by dividing the concentration data by the Federal Standard and computing the common logarithms of these relative concentrations, then proceed to Step 4.

Step 4: Compute the decision variables, go to Step 5.

Step 5: Make the decision by plotting a single point on the decision chart and read off the decision (either noncompliance, no action, or no decision).

Step 6: Obtain the estimate of the average contaminant level from the estimation nomograph.

\subsection{DETAILED DESCRIPTION OF PROCEDURE}

\section{Step 1 - Collect Data}

The available contaminant data consists of the following information:

(a) The concentration measurements: $x_{1}, \ldots, x_{n}$ (average concentrations for the sampling periods).

(b) The times at which these measurements were taken: $t_{1}, \ldots, t_{n}$ (the midpoints of the sampling periods). 


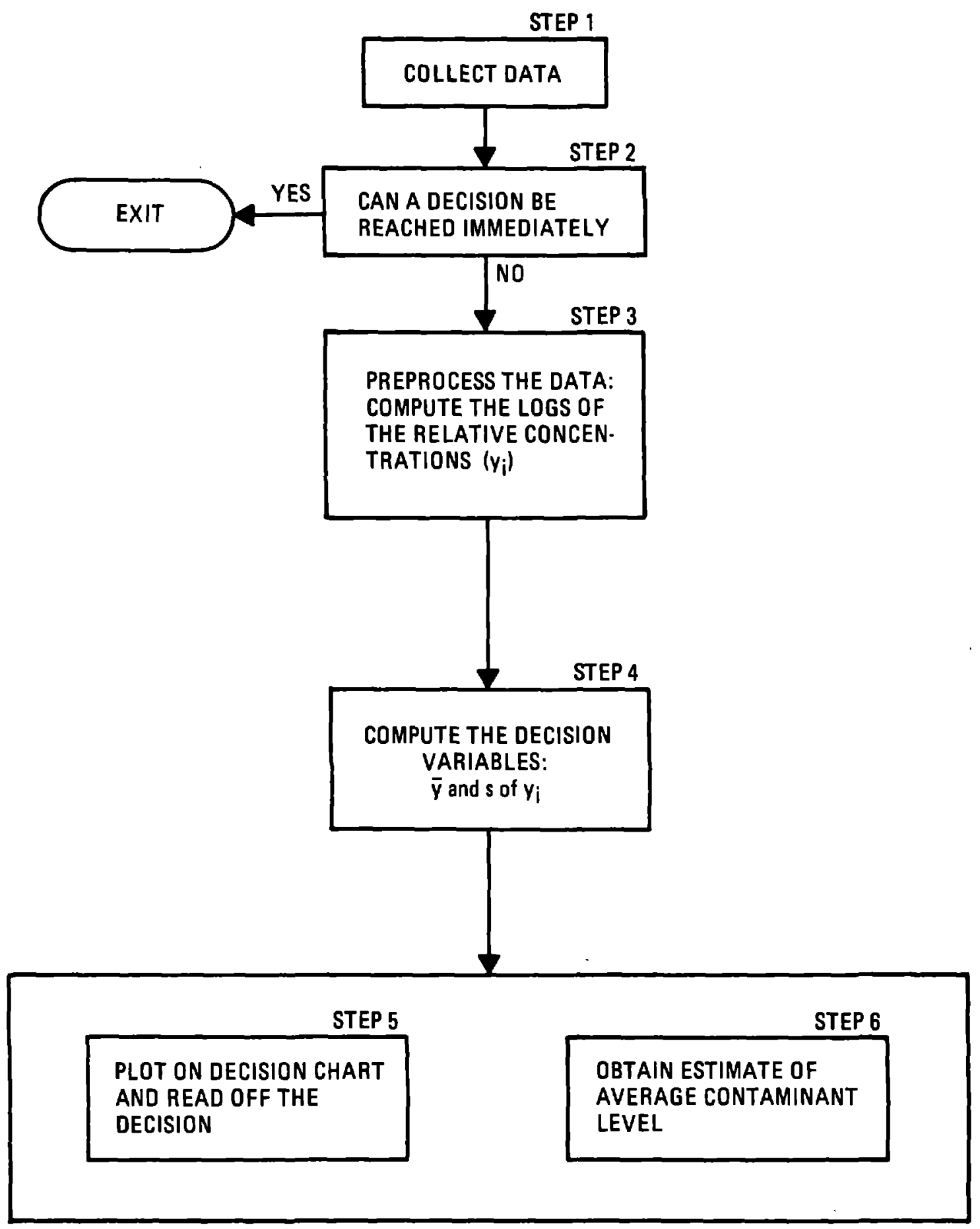

Appendix A Figure 1 - Flow chart for Grab Samples Procedure. 
Technical Remark: One should not attempt to reach a decision about the eight-hour average contaminant level based upon measurements that cover only a small portion (e.g., last two hours) of the eight hour work day.

\section{Step 2 - Can a Decision Be Reached Immediately?}

In some cases it is possible to quickly "eyeball" the concentration data to determine that a state of noncompliance exists. If the minimum of the concentration data is $30 \%$ above the standard, then a state of noncompliance probably exists and an exit from the rest of the steps can usually be made.

\section{Step 3 - Preprocess the Data}

In this step the data is preprocessed to prepare for later analysis.

(a) Calculate the relative concentrations with respect to the applicable Federal Standard.

Let the Federal Standard for the contaminant being investigated be denoted by STD. Then compute the following quantities:

$$
x_{1}=\frac{x_{1}}{S T D}, \quad x_{2}=\frac{X_{2}}{S T D}, \cdots x_{n}=\frac{X_{n}}{S T D}
$$

That is, divide each of the concentration measurements by the standard. The new $x_{1}, x_{2}, \ldots, x_{n}$ are called the relative concentrations. The reason that this division is performed is to make the concentrations of contaminant independent of the particular contaminant being investigated. The "standard" value for the "new" $x_{1}, x_{2}, \ldots, x_{n}$ will always be one.

(b) Compute the common logarithms of the relative concentrations.

In this part of Step 3 , the common logarithms of the relative concentrations are determined. The logarithms of the relative concentrations are denoted by $y_{1}, y_{2}, \ldots, y_{n}$. Therefore,

$$
v_{1}=\log x_{1}, v_{2}=\log : x_{2}, \ldots v_{n}=\log x_{n}
$$

\section{Step 4 - Compute the Decision Variables}

Obtain the sample mean, denoted by $\bar{y}$, and the sample standard deviation, denoted by $s, \bar{y}, s$, and $n$ are the decision variables. 
These variables will be used in determining which of the following decisions should be made (Step 5).

- non-compliance

- no action

- no decision

Also, these variables will be used to estimate the average concentration of contaminant (Step 6).

The computational formula for $\bar{y}$ is:

$$
\bar{y}=\frac{1}{n}\left(\dot{y}_{1}+y_{2}+\ldots+y_{n}\right)
$$

The computational formula for $s$ is:

$$
s=\sqrt{\frac{1}{n-1}\left[\left(y_{1}-\bar{y}\right)^{2}+\left(y_{2}-\bar{y}\right)^{2}+\ldots\left(y_{n}-\bar{y}\right)^{2}\right]}
$$

Or, in a computationally simpler form $s$ is:

$$
s=\sqrt{\frac{1}{n-1}\left[\left(v_{1}^{2}+y_{2}^{2}+\ldots+y_{n}^{2}\right)-n(\bar{v})^{2}\right]}
$$

Step 5 - Make the Decision by Plotting the Decision Variables $\bar{y}$, s on the Decision Chart

Make the decision by plotting the decision variables $\bar{y}, s$ on the decision chart, contained in Section 4.

The decision chart contains the following:

- A vertical axis for the $\bar{y}$ decision variable

- A horizontal axis for the s decision variable

- A set of curves which form the boundaries to the noncompliance, no decision, and no action decision regions. Each of these boundaries is a function of the number of observations. The number of observations is denoted by $n$. The values of $n$ are from $n=3$ to 25 .

- The decision region plot is set up to have the following probability structure:

(i) The probability of asserting "non-compliance", when true situation is "compliance", is at most $5 \%$.

(ii) The probability of asserting "no action" when the true situation is "non-compliance" is at most $5 \%$. 
Technical Remark: Recall that (i) and (ii) are denoted technically as the size of Type I and Type II errors, respectively.

To use the decision region plot proceed as follows:

- Plot the decision variables $\bar{y}, s$ on the vertical and horizontal axis, respectively, to obtain the decision point.

- If the decision point lies above the upper curve corresponding to the number of measurements $n$, then decide "non-compliance".

- If the decision point lies below the lower curve corresponding to the number of measurements $n$, then decide "no action".

- If the decision point is between two curves, then no decision can be made.

- If the value of $\bar{y}$ is out of range, either below -.9 or above .3, then usually "eyeball" interpolation will suffice to obtain the decision.

- If the value of $s$ is greater than .5 this indicates that one or more of the concentration measurements is "way out of 7 ine". This indicates usually that a state of non-compliance exists. Again, in this case, eyeball interpolation should be used.

\section{Step 6 - Obtain Estimate of the Average Contaminant Level From The Estimation Nomograph.}

The decision variables $\bar{y}$ and $s$ are also used to obtain the estimate of the value of the average contaminant level. The estimate is obtained using the estimation nomographs which are contained in Section 4 . Estimation nomographs contain the following:

- A left-hand vertical axis for the $\bar{y}$ decision variable.

- A horizontal axis for the s decision variable.

- A right-hand vertjcal axis for reading off the average contaminant level denoted by M/STD.

- Each estimation nomograph has a value $n$ associated with it, where $n$ is the number of data points

The procedure for using an estimation nomograph is as follows:

- Select the appropriate nomograph corresponding to the number of samples of the contaminant. 
- Plot the decision variables $\bar{y}$ and $s$, with $\bar{y}$ on the vertical axis and $s$ on the horizontal axis.

- Follow the nomograph curve nearest to the plotted point to the M/STD axis on the right-hand side of the nomograph.

- Interpolate between two xalues of $\hat{M} / S T D$ to obtain the appropriate M/STD. If the value of M/STD is multiplied by STD then the estimate of the average concentration $M$ will be obtained.

If the values of $\bar{y}$ or $s$ are outside the range of the estimation nomograph, then the arithmetic mean of the measurements

$$
\bar{x}=\frac{1}{n}\left(x_{1}+x_{2}+\ldots+x_{n}\right)
$$

is to be used to estimate the average concentration. 


\section{EXAMPLES OF PROCEDURES}

This section contains detailed examples of the procedure. Specific examples are provided to illustrate and demonstrate the use of the procedure for:

- Computing the decision variables

- Making the decision (i.e., either non-compliance, no action or no decision)

- Obtaining estimates of contaminant level.

This section will also demonstrate in a step-by-step manner the organization of computations that are required for using the procedure as outlined in Figure 1. In particular, this section will illustrate:

- The use of a computational worksheet

- The use of the decision chart and estimation nomographs.

The examples illustrated in this section are intended to give the reader some insight into the way the methodology works.

\subsection{Example 1}

The measurements of carbon monoxide concentration yielded the data displayed in Table 3.1 for a particular employee in an industrial plant.

$\begin{array}{lrrrrrrrrrr}\text { TIME OF DAY } & 9 & 10 & 11 & 12 & 13 & 14 & 15 & 16 & 17 & 18 \\ \begin{array}{l}\text { CONCENTRATION } \\ \text { OF CO (PPM) }\end{array} & 45 & 50 & 75 & 40 & & 85 & & 20 & & \end{array}$

\section{TABLE 3.1 RAW DATA FOR EXAMPLE \#1}

Table 3.1 summarizes the data collection, Step 1. For this example, the Time row in the table indicates the actual clock time at which the concentration measurements were obtained (mid-point of sampling interval). 
The Federal Standard for $\mathrm{CO}$ is $50 \mathrm{ppm}$. By "eyeballing" the data above $50 \mathrm{ppm}$ it cannot be determined if a state of non-compliance exists, therefore Step 3 must be done next.

Table 3.2 illustrates a worksheet for executing Step 3 and Step 5 (preprocessing the data and computing the decision). Columns 1 and 2 of the worksheet are the raw data recopied. Column 3 is the concentration divided by the Federal Standard, rounded to two places to the right of the decimal point.

Column 4 contains the value of the common logs (base 10) of the values in Column 3 .

Step 4 must now be computed. Aga in the worksheet Table 3.2 is used to compute the decision variables. This is accomplished by computing column 5 , which is the square of column 4 and adding the values of column 4 and 5 and putting the respective values in the bottom margins denoted by "SUM". The values for this example are -0.14 and 0.26 , respectively. Note that all calculations are rounded to two significant figures. The values of the decision variables can now be computed using the equations (3) and (4b). The calculations are illustrated on the worksheet below Table 3.2. From the worksheet, the values of the three decision variables can be seen to be:

$$
\begin{aligned}
n & =6 \\
\bar{y} & =-0.02 \\
s & =.23
\end{aligned}
$$

Remark on Calculations:

The following rules should be followed in performing the calculations on the worksheet.

- Rute 1. Compute and round the logarithms to two places to the right of decimal point.

- Rule 2. Compute the squares on the worksheet to four places to the right of the decimal point. Round to two places to the right of the decimal point after forming sum.

- Rule 3. Compute the expressions for $s$ on the worksheet to four places to the right of the decimal point. Round to two places to the right of decimal point after forming square root.

- Rule 4. All other calculations are performed and rounded to two places past the decimal point. However, it may be necessary to carry additional significant digits in the terms of a difference if the leading digits of both terms are identical (as 22.15 and 22.34). 
Note that the calculations on the worksheet can easily be implemented on advanced pocket scientific calculators which have hardwired programs for logs, arithmetic mean, and standard deviation. The worksheet is primarily set up for a calculator that performs only the elementary operations.

Now Steps 5 and 6 can be executed. Namely, in Step 5 the decision of non-compliance, no decision or no action can be determined; and in Step 6 , an estimate of the average contaminant level can be determined.

Using the decision region plot in Section 4, plot the value of $s$ on the horizontal axis and the value of $\bar{y}$ on the vertical axis. Figure 3.1 illustrates the use of the plot. The result of plotting the decision variables is denoted by " $A$ " in Figure 3.1. It is observed that for this example the "No Decision" choice must be made. This is because the point "A" Ties between the boundaries of the $n=6$ curves in the no decision region. Observe that the $n=6$ curve must be interpolated between the $n=5$ and $n=7$ curve. This means that neither the non-compliance nor the no action decision can be asserted with sufficiently high confidence.

To estimate the average contaminant level, the estimation nomograph with $n=5$ or 6 (nomograph with values of $n=5$ or $n=6$ ) must be used because the number of concentration data is equal to 6 . Plotting $s$ along the horizontal axis and $\bar{y}$ along the vertical axis yields the point "B" in Figure 3.2. Reading the value corresponding to the curve on which "B" 1 ies the yalue of $\hat{M} / S T D$ is seen to be equal to roughly $3 / 7$ of the way from the $1.0 \mathrm{M} / \mathrm{STD}$ to the $1.2 \mathrm{M} / \mathrm{STD}$ values.

Thus the value of $\hat{M} / S T D$ to be used is:

$$
3 / 7(1.2-1.0)+1.0=1.09
$$

This is the simple interpolation method.

This is the estimate of the average contaminant level divided by the standard. Since the standard is $50 \mathrm{ppm}$ for $\mathrm{CO}$, then $(1.09)(50)=54.5 \mathrm{ppm}$ is the estimate of the average contaminant level for this data. Thus, it can be concluded that even though the estimated average level of $\mathrm{CO}$ above the standard, a state of non-compliance cannot be asserted. The arithmetic average of the contaminant can be seen to be $52.50 \mathrm{ppm}$. It is important to note that this arithmetic average is different than the average value of the contaminant. 


\begin{tabular}{|c|c|c|c|c|}
\hline 1 & 2 & 3 & 4 & 5 \\
\hline $\begin{array}{c}\text { TIME OF } \\
\text { DAY }\end{array}$ & CONC. & $\frac{\text { CONC. }}{\text { STD }}$ & $\operatorname{LOG}\left[\frac{\operatorname{CONC}}{\mathrm{STD}}\right]$ & $(\mathrm{COL} .4)^{2}$ \\
\hline 9 & 45 & 0.90 & -0.05 & 0.0025 \\
\hline 10 & 50 & 1.00 & 0.00 & 0.0000 \\
\hline 11 & 75 & 1.50 & 0.18 & 0.0324 \\
\hline 12 & 40 & 0.80 & -0.10 & 0.0100 \\
\hline 14 & 85 & 1.70 & 0.23 & 0.0529 \\
\hline 16 & 20 & 0.40 & -0.40 & 0.1600 \\
\hline SUM & & & -0.14 & 0.26 \\
\hline
\end{tabular}

\section{Decision Variables}

$$
\begin{aligned}
& n=\frac{6}{y} \text { data values } \\
& \bar{y}=\sqrt{\frac{1}{n-1}[(\text { Sum Col. } 4=\underline{-0.02}} \\
& =\sqrt{n}-\frac{1}{n}(\text { Sum Col. 4) }]=.23
\end{aligned}
$$




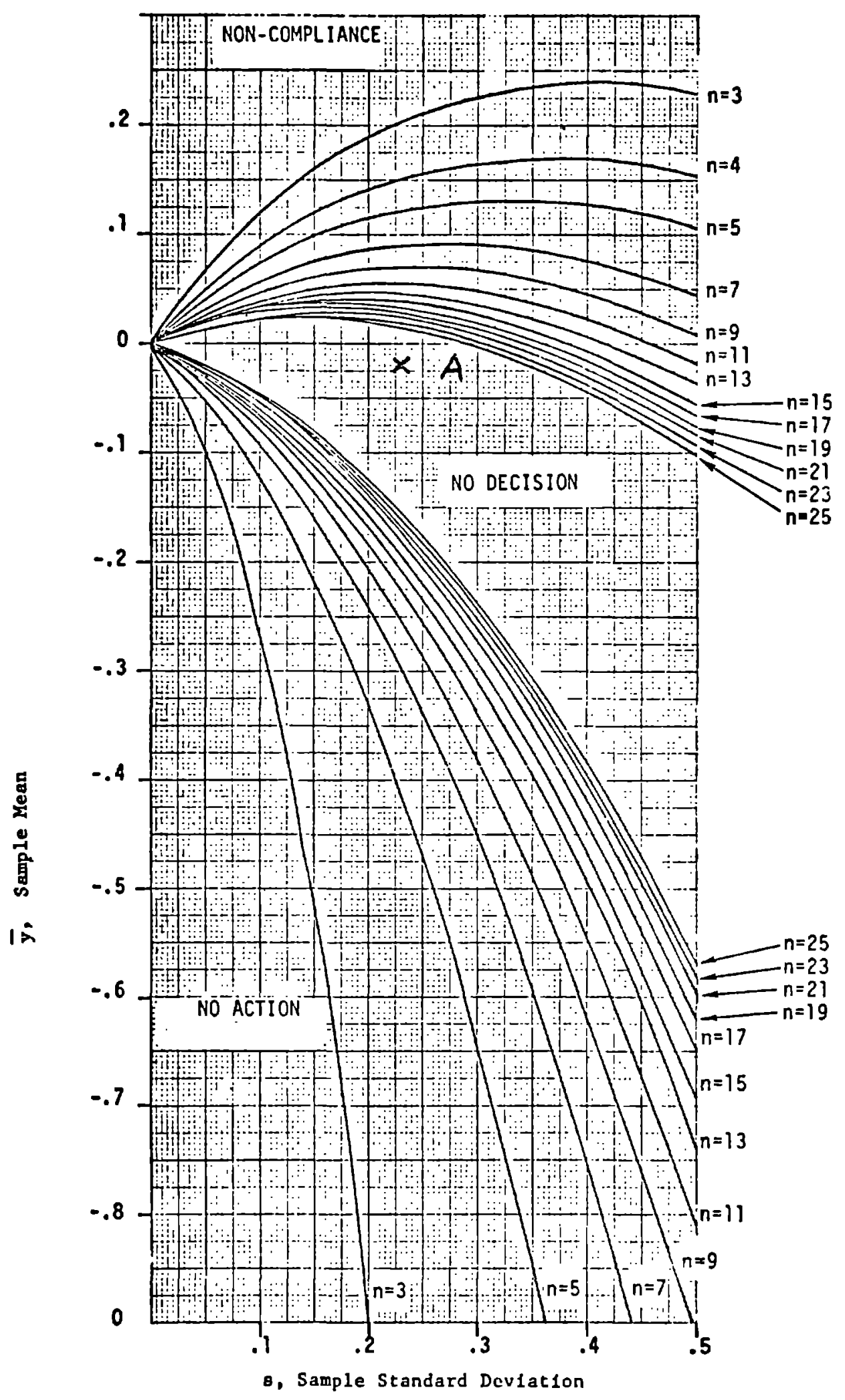

Figure 3.1 Decision regions 


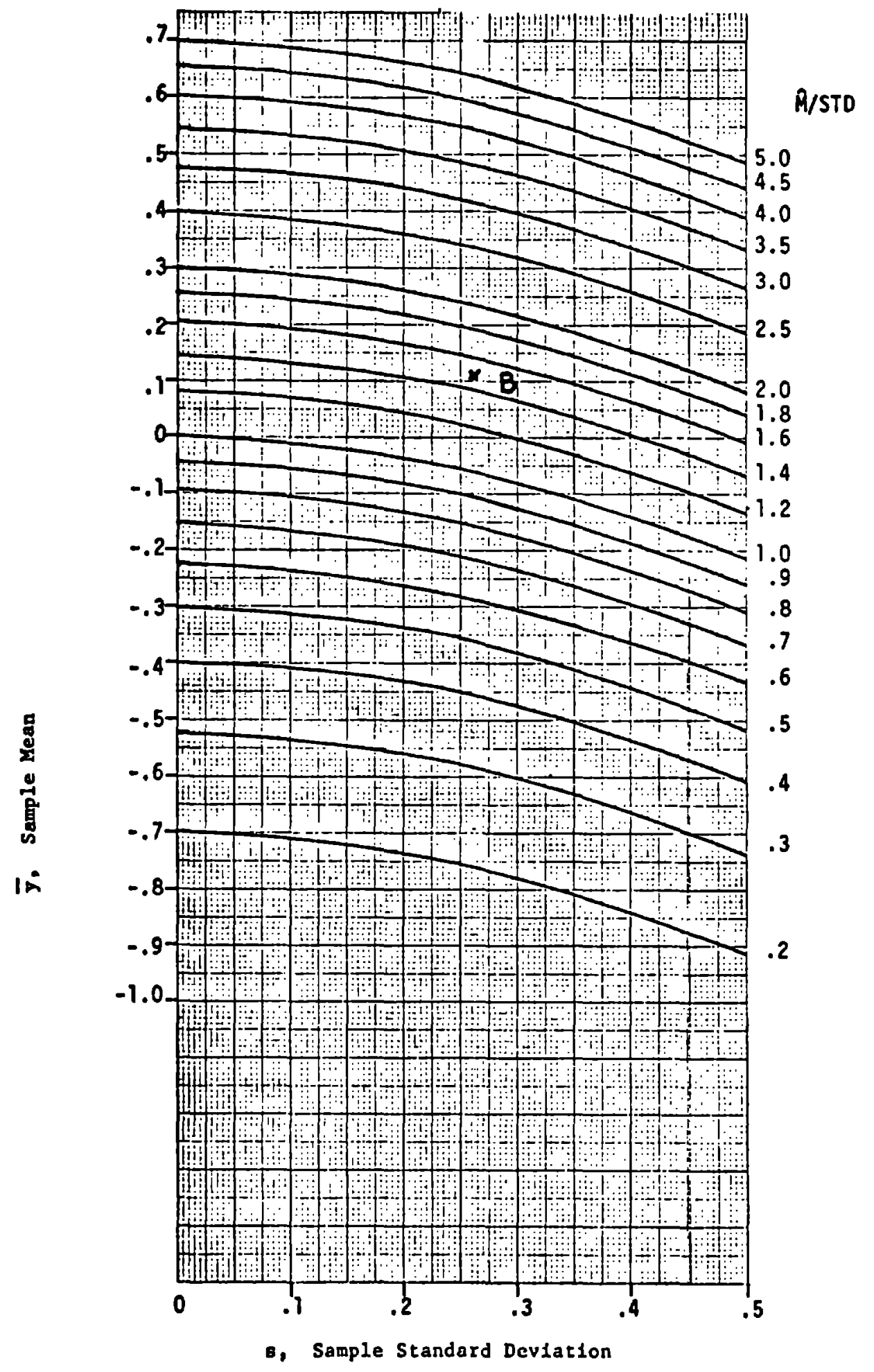

Figure 3.2 Estimation nomograph for Example \#1 ( $n=6)$ 


\section{Example \#2}

A Mercury vapor detector gave the following readings at the corresponding times in an industrial plant. The values are in $\mathrm{mg} / \mathrm{m}^{3}$. The Federal Standard for Mercury vapor is $0.10 \mathrm{mg} / \mathrm{m}^{3}$.

$\begin{array}{lllllllllll}\text { TIME } & 9 & 10 & 11 & 12 & 13 & 14 & 15 & 16 & 17 & 18\end{array}$

CONCENTRATION

$\begin{array}{lllllll}\mathrm{OF} \mathrm{Hg}\left(\mathrm{mg} / \mathrm{m}^{3}\right) & .06 & .20 & .09 & .09 & .09 & .30\end{array}$

\section{TABLE 3.3 RAW DATA FOR EXAMPLE \#2}

Since it cannot be decided if a state of non-compliance exists by merely looking at the data Steps 4,5 , and 6 will be performed.

The worksheet is presented in Table 3.4. For detailed explanation of the worksheet see Example \#1.

An examination of the decision chart, Figure 3.3, shows that for $n=6, \bar{y}=.11$ and $s=.26$, a "non-compliance" decision must be asserted for this case. The decision point is plotted and denoted by "A" in Figure 3.3. This is because the point "A" lies above the interpolated curve for $n=6$ on the decision region plot.

To estimate the average concentration of $\mathrm{Hg}$ vapor for this sample, the estimation nomograph with $n=5$ or 6 , is to be used because the sample size is 6 . Using the estimation nomograph it can be seen that for $n=6$, estimation point is plotted and denoted by "B" in Figure 3.4. Thus, using simple interpolation the value of the average concentration will be :

$$
1.4+.5(1.6-1.4)=1.50
$$

The average value of the $\mathrm{Hg}$ concentration for the area sampled in $\mathrm{mg} / \mathrm{m}^{3}$ is:

$$
\hat{M}=\left(\frac{\hat{M}}{S T D}\right)(S T D)=(1.50)(0.10)=0.15 \mathrm{mg} / \mathrm{m}^{3}
$$

rounded to two significant digits. 


\begin{tabular}{|c|c|c|c|c|}
\hline 1 & 2 & 3 & 4 & 5 \\
\hline $\begin{array}{c}\text { TIME OF } \\
\text { DAY }\end{array}$ & CONC. & $\frac{\text { CONC. }}{\text { STD }}$ & $\operatorname{LOG}\left[\frac{\mathrm{CONC} .}{\mathrm{STD}}\right]$ & $(\mathrm{COL} .4)^{2}$ \\
\hline 9 & 0.06 & 0.60 & -0.22 & 0.0484 \\
\hline 10 & 0.20 & 2.00 & 0.30 & 0.0900 \\
\hline 11 & 0.09 & 0.90 & -0.05 & 0.0025 \\
\hline 14 & 0.16 & 1.60 & 0.20 & 0.0400 \\
\hline 15 & 0.09 & 0.90 & -0.05 & 0.0025 \\
\hline 16 & 0.30 & 3.00 & 0.48 & 0.2304 \\
\hline SUM & & & .66 & .41 \\
\hline
\end{tabular}

TABLE 3.4

Decision Variables

$$
\begin{aligned}
& n=\frac{6}{y}=\frac{\text { Sum Col. } 4}{n}=.11 \\
& s=\sqrt{\frac{1}{n-T}\left[(\text { Sum Col. } 5)-\frac{1}{n}(\text { Sum Col. } 4)^{2}\right]}=.26
\end{aligned}
$$




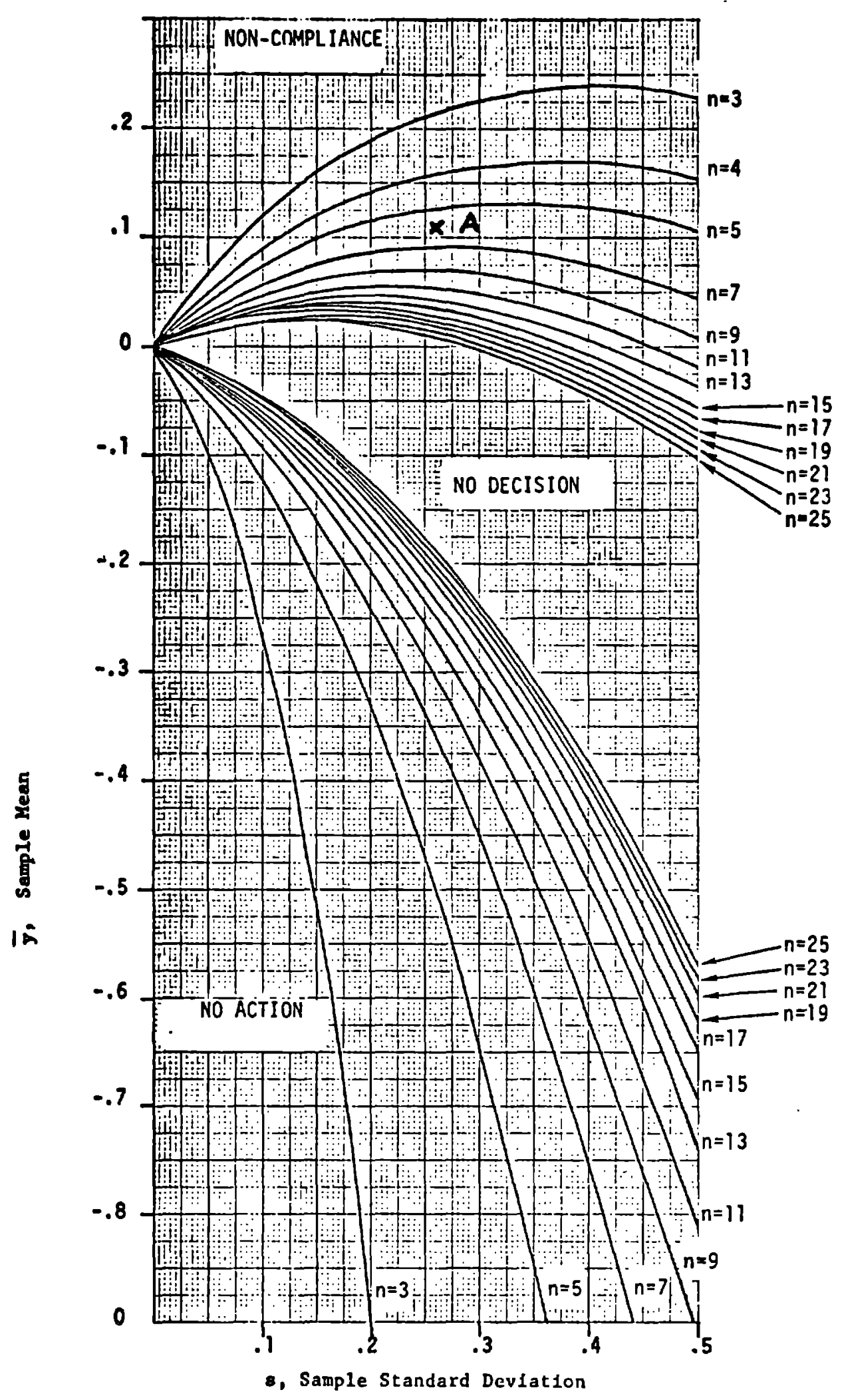

Figure 3.3 Decision regions for Example \#2 


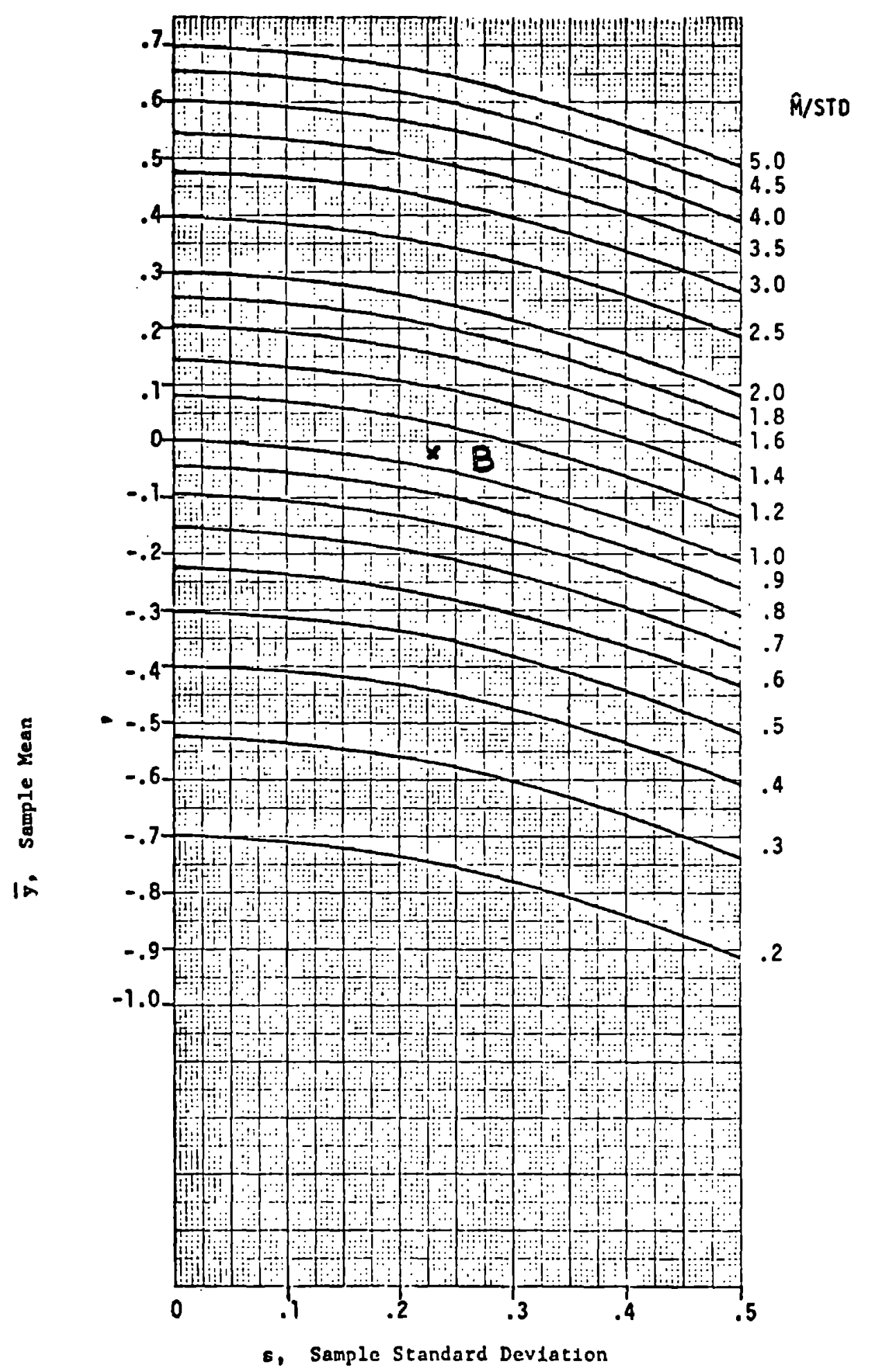

Figure 3.4 Estimation nomograph for Example \#2 $(n=6)$ 


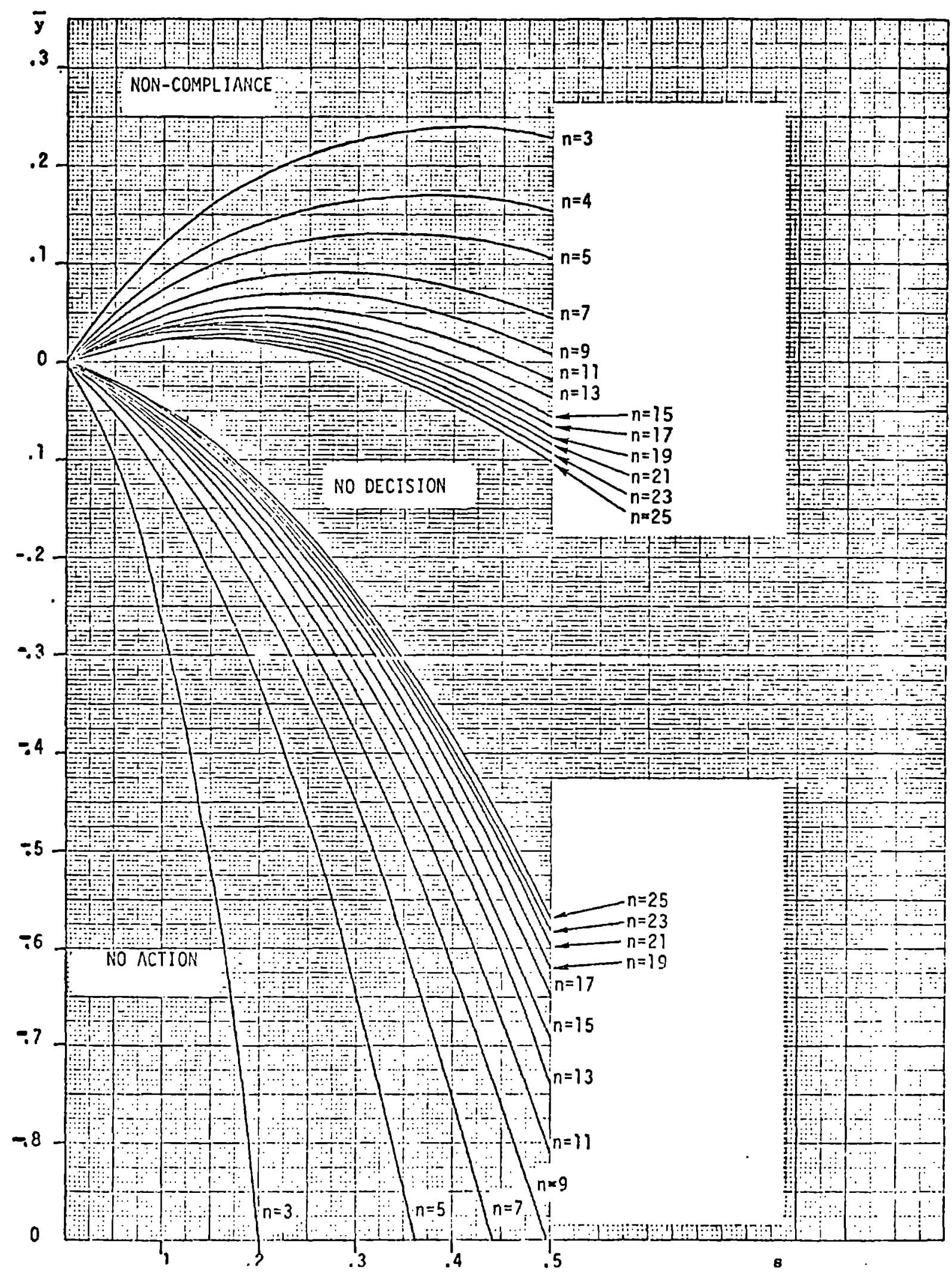

Figure 4.1 Decision regions 


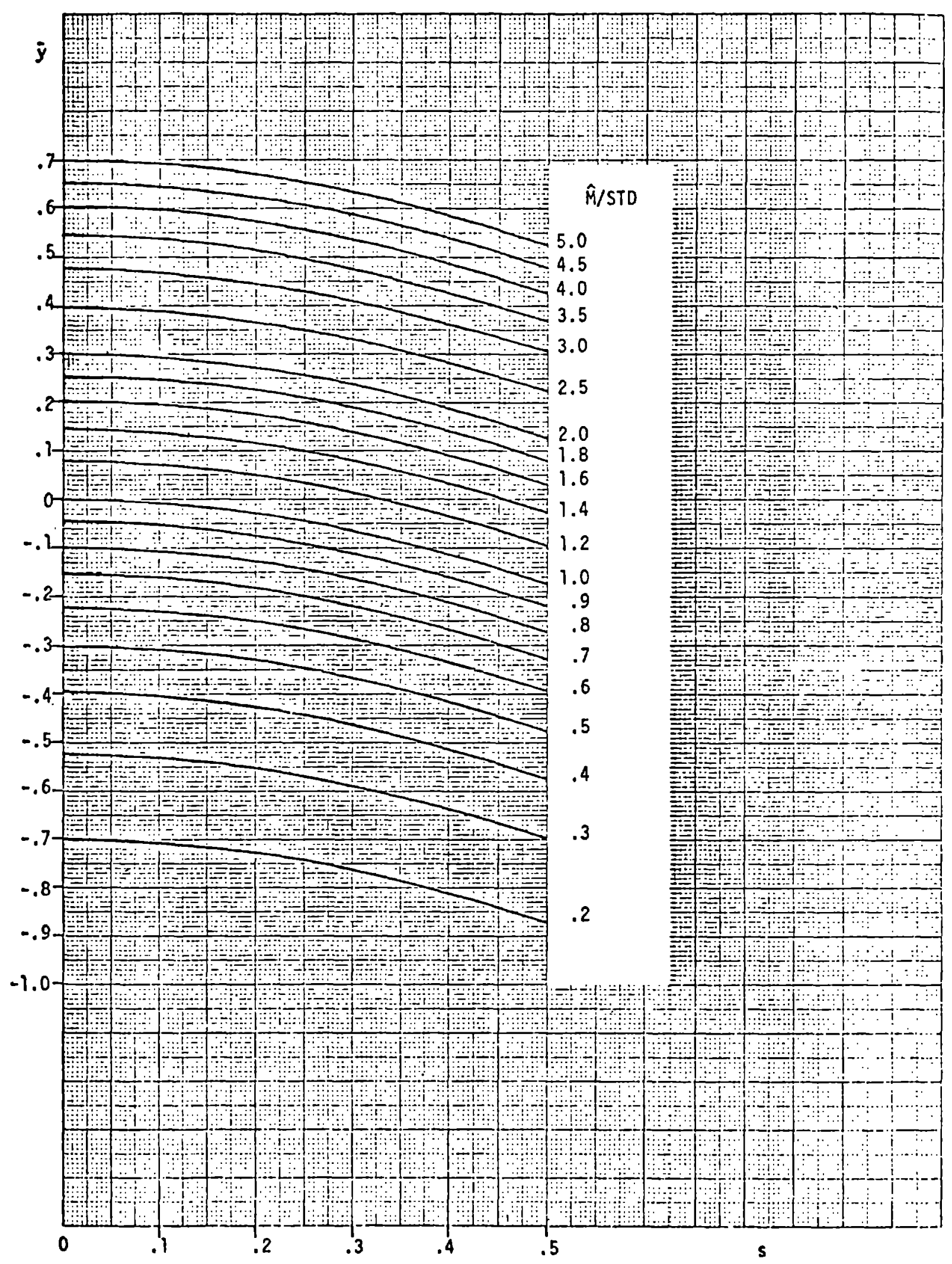

Figure 4.2 Estimation nomograph for $n=3$ or 4 


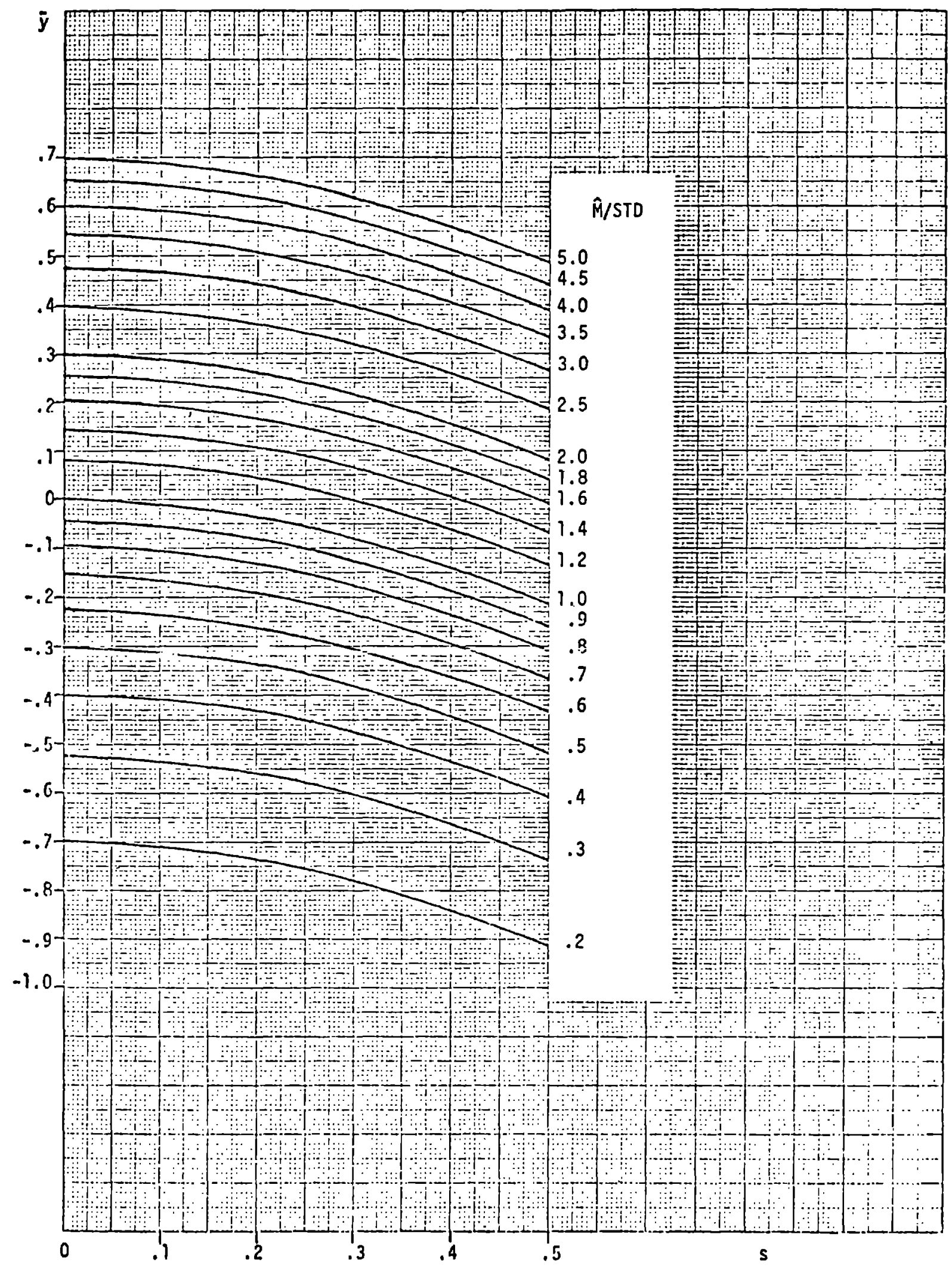

Figure 4.3 Estimation nomograph for $n=5$ or 6 


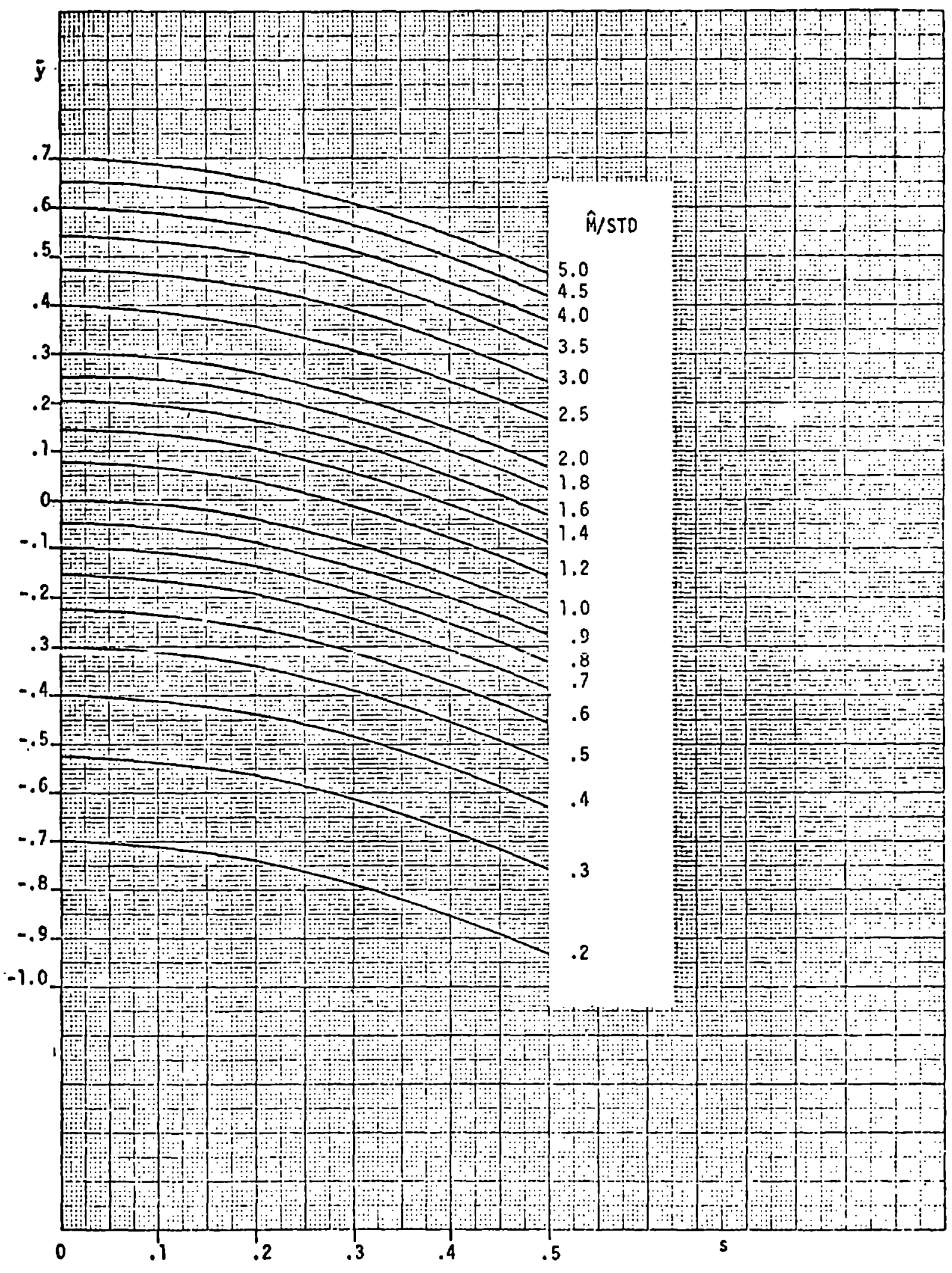

Figure 4.4 Estimation nomograph for $n=7$ or greater 